\title{
Skin protective effects of RM191A, a novel superoxide dismutase mimetic
}

Artur Shariev ${ }^{1}$, Alistair J. Laos ${ }^{2}$, Donna Lai ${ }^{3}$, Sheng Hua ${ }^{3}$, Anna Zinger ${ }^{4}$, Christopher R. McRae $^{5}$, Llewellyn S. Casbolt ${ }^{6}$, Valery Combes ${ }^{7}$, Tzong-tyng Hung ${ }^{8}$, Katie M. Dixon ${ }^{1}$, Pall Thordarson $^{2}$, Rebecca S. Mason ${ }^{9}$, Abhirup Das ${ }^{10, *}$

${ }^{1}$ Department of Anatomy and Histology, School of Medical Sciences, University of Sydney, Australia

${ }^{2}$ School of Chemistry, The Australian Centre for Nanomedicine and the ARC Centre of Excellence in Convergent Bio-Nano Science and Technology, University of New South Wales, Sydney, Australia

${ }^{3}$ Bosch Institute, Faculty of Medicine and Health, University of Sydney, Australia

${ }^{4}$ Department of Pathology, Faculty of Medicine and Health, University of Sydney, Australia

${ }^{5}$ Department of Chemistry and Biomolecular Sciences, Macquarie University, Sydney, Australia

${ }^{6}$ Department of Biomedical Sciences, Faculty of Medicine and Health Sciences, Macquarie University, Sydney, Australia

${ }^{7}$ School of Life Sciences, University of Technology, Sydney, Australia

${ }^{8}$ Biological Resources Imaging Laboratory, University of New South Wales, Sydney, Australia

${ }^{9}$ Department of Physiology, School of Medical Sciences, University of Sydney, Australia

${ }^{10}$ St. George and Sutherland Clinical School, University of New South Wales, Sydney, Australia

Correspondence: *abhirupdas@unsw.edu.au 


\section{HIGHLIGHTS}

- Superoxide dismutase mimetic RM191A is a highly stable copper $\left(\mathrm{Cu}^{2+}-\mathrm{Cu}^{3+}\right)$-polyglycine coordination complex

- RM191A exhibits potent antioxidant (10-fold more than that of superoxide dismutase) properties in vitro

- $\quad$ RM191A exhibits potent anti-inflammatory properties in vitro and in vivo

- RM191A protects human skin explants against UV-induced oxidative stress and DNA damage

- RM191A is non-toxic and readily bioavailable in mice

- RM191A attenuates TPA-induced skin inflammation and improves wound healing in mice 


\begin{abstract}
Superoxide dismutase (SOD) is known to be protective against oxidative stress-mediated skin dysfunction. Here we explore the potential therapeutic activities of RM191A, a novel SOD mimetic, on skin. RM191A is a water soluble, dimeric copper $\left(\mathrm{Cu}^{2+}-\mathrm{Cu}^{3+}\right)$-centred polyglycine coordination complex. It displays 10 -fold higher superoxide quenching activity compared to SOD as well as significant anti-inflammatory activity through beneficial modulation of several significant inflammatory pathways in cells.

We tested the therapeutic potential of RM191A in a topical gel using a human skin explant model and observed that it significantly inhibits UV-induced DNA damage in the epidermis and dermis, including cyclobutane pyrimidine dimers (CPD), 8-oxo-guanine (8-oxoG) and 8-nitroguanine (8NGO). RM191A topical gel is found to be safe and non-toxic in mice following month-long daily dosing at $0.19 \mathrm{~mL} / \mathrm{kg}$ body weight. Moreover, it significantly accelerates excisional wound healing, and reduces 12-O-tetradecanoylphorbol-13acetate (TPA)-induced skin inflammation in mice.
\end{abstract}


bioRxiv preprint doi: https://doi.org/10.1101/2020.05.10.086694; this version posted May 11,2020 . The copyright holder for this preprint (which

was not certified by peer review) is the author/funder, who has granted bioRxiv a license to display the preprint in perpetuity. It is made available under aCC-BY-NC-ND 4.0 International license.

\section{KEYWORDS}

Skin disorders; SOD mimetic; antioxidant; skin inflammation; UV protection; wound healing. 


\section{INTRODUCTION}

Our skin acts as the first barrier of defence against various infections, trauma and environmental factors. Risk factors like ultraviolet (UV) radiation, environmental pollutants, xenobiotics, ageing, wounds, chronic inflammation and inflammatory skin diseases, such as psoriasis and atopic dermatitis, are major impediments against the proper maintenance of the skin barrier (1-4). Oxidative stress, which compromises proper skin integrity, is one of the most common features among these various risk factors (5-7). An over-abundance of oxidants or catalyst producing free radicals, such as reactive oxygen species (ROS) and reactive nitrogen species (RNS), and in parallel the failure of the endogenous antioxidant defence system in skin cells, primarily contribute to the formation of oxidative stress in skin (8-10). Furthermore, oxidative stress and inflammation are closely interconnected pathophysiological processes that are known participants in the pathogenesis of numerous skin diseases (11-14). Inhibition of oxidative stress is therefore important for maintenance of normal skin function.

Superoxide dismutase (SOD) enzymes catalyse the disproportionation of the cytotoxic superoxide $\left(\mathrm{O}_{2}{ }^{-}\right)$free radical to hydrogen peroxide and oxygen and play a significant role in the attenuation of oxidative stress in our body (15). SODs have been reported to be protective against many skin disorders (16). They sequester free radicals which are formed following UV exposure and have the potential to damage our DNA. Such DNA damage has been shown to be a major contributing factor to skin carcinogenesis. Due to its powerful antioxidant potential, endogenous SOD also exhibits potent anti-inflammatory properties by inhibiting the expression of ROS-sensitive transcription factors (17). SOD plays a major role in wound healing $(18,19)$. For these reasons, exogenous SOD was contemplated as a therapeutic agent for the treatment of various skin disorders. However, the lack of clinical development of exogenous SOD is due to its large size (molecular weight $\approx 30 \mathrm{kDa}$ ), low cell permeability, short circulating half-life, antigenicity, and high manufacturing costs (20). To overcome these issues, much focus has been placed on the synthesis of low-molecular-weight, stable compounds that mimic SOD's antioxidant activity.

There are three kinds of SOD enzymes. SOD2 is localized in mitochondria and contains manganese. Both cytosolic SOD1 and extracellular SOD3 enzymes contain a redox active copper atom $\left(\mathrm{Cu}^{2+}\right)$, which is fundamental to the dismutation of the superoxide free radical, and a zinc atom (21-23). Interestingly, it has been established that if the zinc atom of either SOD is replaced with a copper atom, this di-copper form has the same free radical/superoxide scavenging activity as the endogenous enzymes (24). A significant number of the SOD mimetics reported in the literature focus on replicating the activity of SOD2. These include a variety of manganese porphyrin complexes, manganese (II) penta-azamacrocyclic complexes, and manganese (III) salen complexes (25). Topical application of these SOD mimetics demonstrated potential benefits for the treatment of skin disorders $(26,27)$. Only a small number of SOD mimetics utilising the unique copperbased bivalent configuration of SOD1 have been reported, however, their biological activities were never demonstrated $(24,28,29)$.

Here we report for the first time, a highly stable, unique copper $\left(\mathrm{Cu}^{2+}-\mathrm{Cu}^{3+}\right)$-centred polyglycine coordination complex - RM191A, which has been demonstrated through extensive analytical, in vitro and in vivo evaluation to possess robust antioxidant and antiinflammatory activities. Our work indicates biological activity of topically applied RM191A across a broad spectrum of skin disorders. Specifically, we report protection of the 
epidermis, dermis and associated DNA following exposure to UV radiation in human skin explants; acceleration of wound healing; and significant anti-inflammatory and antioxidant activities in skin. We posit that these activities are a result of the complex's SOD-like activity as well as its beneficial modulation of a number of important gene signalling pathways.

\section{MATERIAL AND METHODS}

RM191A Synthesis. RM191A was synthesized according to a proprietary protocol patented by RRMedSciences. RM191A gel formulation (5\% RM191A hydrogel) consists of $21 \mathrm{mg}$ of RM191A in $1 \mathrm{~mL}$ of hydrogel base.

Elemental Analysis. Elemental microanalysis was performed using Perkin Elmer PE2400 elemental analyser (Macquarie University).

FTIR. FTIR spectroscopy was performed using Nicolet IS5 FTIR Spectrometer at Macquarie University.

Cryo-TEM. After diluting $2 \mathrm{mg}$ of the sample into $1 \mathrm{~mL}$ of pure water (500 fold dilution), the sample $(6 \mu \mathrm{L})$ was pipetted onto 300 mesh copper grids with a lacey formvar film (GSCu300FL-50, ProSciTech, Australia). The sample droplet was allowed to equilibrate for 30 seconds at room temperature and $90 \%$ relative humidity, before being blotted from one side for 1.8 seconds. The blotted grid was subsequently plunged into liquid ethane held at $-174^{\circ} \mathrm{C}$, excess ethane was blotted away with a piece of pre-cooled filter paper, and the vitrified grid stored in liquid nitrogen. The samples were then analysed by cryoTEM at UNSW Mark Wainwright Analytical Centre.

DOSY. The DOSY experiments were carried out on a Bruker Avance $400 \mathrm{MHz}$ NMR in $\mathrm{D}_{2} \mathrm{O}$ at $25^{\circ} \mathrm{C}$ with a BBFO probe using 3-9-19 water suppression at Mark Wainwright Analytical Centre, UNSW.

X-ray crystallography. Blue solid RM191A was crystallised from supernatant generated by addition of ethanol to reaction mix. Powder diffraction was performed on a Panalytical Empyrean Bragg-Brentano geometry instrument fitted with a cobalt X-ray source at UNSW Mark Wainwright Analytical Centre.

Measurement of SOD activity. We employed a modified version of the method described by Beauchamp and Fridovich (30). The objective was to create a reaction mixture that successfully generates known quantities of the $\mathrm{O}_{2}{ }^{-}$free radical but does so at a $\mathrm{pH}$ at which RM191A is stable (pH 6.5 - 7.8). Nitro Blue Tetrazolium (NBT) was selected as an indicator to measure and compare the superoxide scavenging activities of both bovine SOD and RM191A. This assay utilized photochemical events to generate $\mathrm{O}_{2}{ }^{-}$in a sodium tetraborate buffered solution of acetone and isopropanol which was then irradiated by high energy UV light at $254 \mathrm{~nm}$ (Mercury Vapour Lamp) to create $\mathrm{O}_{2}^{-}$in the solution. SOD and SOD-like substances inhibited the formation of the blue formazan by neutralising the superoxide free radicals as they were forming. Blue formazan has a characteristic UV absorbance at $560 \mathrm{~nm}$. UV absorbances of the reaction solutions were measured at $560 \mathrm{~nm}$ following irradiation with UV light to determine the in situ superoxide free radical scavenging activity of both bovine SOD and RM191A. The UV-vis spectrum of both SOD 
and RM191A did not exhibit any absorbance at $560 \mathrm{~nm}$ (Fig. S2A). The reaction solution consists of $0.5 \mathrm{~mL}$ of $200 \mu \mathrm{mol} / \mathrm{L} \mathrm{NBT}$ in phosphate buffer $(\mathrm{pH}=7.8)$ and $0.5 \mathrm{~mL}$ of a $200 \mu \mathrm{mol} / \mathrm{L}$ solution of the test compound in $5.0 \mathrm{~mL}$ of $5 \mathrm{~mol} / \mathrm{L}$ isopropanol. $15 \mathrm{mg}$ acetone $(20 \mu \mathrm{L})$ was added to begin the reaction. The reaction mixture was placed in UV light at $254 \mathrm{~nm}$ (mercury vapour lamp) for 1 minute and then transferred to a spectrometer to measure absorbance at $560 \mathrm{~nm}$. The assay was repeated by adding, $1.0,1.25,1.5,1.75,2.0 \mathrm{~mL}$ of a $200 \mu \mathrm{mol} / \mathrm{L}$ solution of the test compound bringing total volume to $5.0 \mathrm{~mL}$ with $5 \mathrm{~mol} / \mathrm{L}$ isopropanol.

Cells. N27 cells were cultured in RPMI 1640 medium supplemented with $10 \%(\mathrm{v} / \mathrm{v})$ fetal calf serum (FCS), $2 \mathrm{mM}$ L-glutamine and penicillin/streptomycin (P/S) solution at $37^{\circ} \mathrm{C}$ with $5 \% \mathrm{CO}_{2}$. RAW 264.7 cells were cultured in DMEM medium supplemented with $10 \%$ FCS and $1 \% \mathrm{P} / \mathrm{S}$ at $37^{\circ} \mathrm{C}$ with $5 \% \mathrm{CO}_{2}$. Human umbilical vein endothelial cells (HUVEC) and $\mathrm{hCMEC} / \mathrm{D} 3$ were cultured in RPMI $+10 \% \mathrm{FCS}$ at $37^{\circ} \mathrm{C}$ with $3 \% \mathrm{O}_{2}$ and $5 \% \mathrm{CO}_{2}$. Adult normal human dermal fibroblasts (NHDF) were cultured in FGM-2 fibroblast growth medium-2 (Lonza) at $37^{\circ} \mathrm{C}$ with $3 \% \mathrm{O}_{2}$ and $5 \% \mathrm{CO}_{2}$.

Cell viability. Cell viability was assessed using propidium iodide exclusion assay as described before (31). Briefly, cells $\left(0.1 \times 10^{5}\right.$ cells) were seeded in a 48-well plate and incubated with different concentrations of RM191A or gel alone for $24 \mathrm{hrs}$. After $24 \mathrm{hrs}$, cells were trypsinized, stained with propidium iodide (PI, $10 \mu \mathrm{g} / \mathrm{mL})$ and the number of PI negative (PI -ve) cells were determined by flow cytometry (BD FACSCanto II, Biological Resources Imaging Laboratory, UNSW). In hydrogen peroxide-mediated oxidative stress assay, N27 cells were first exposed to $200 \mu \mathrm{M}$ hydrogen peroxide for 30 minutes and then treated with $21 \mu \mathrm{g} / \mathrm{mL}$ RM191A (gel as control) for $4 \mathrm{hrs}$, after which cell viability was measured using flow cytometry. Alternatively, cell viability was determined using MTT assay kit (Sigma) according to manufacturer's protocol.

LPS stimulation assay. LPS-stimulated ROS generation in RAW 264.7 cells was determined as previously reported (32). RAW 264.7 cells $\left(10^{6}\right)$ were stimulated with LPS $(10 \mathrm{ng} / \mathrm{mL})$ for $6 \mathrm{hrs}$ with gel or RM191A $(21 \mu \mathrm{g} / \mathrm{mL})$ for $6 \mathrm{hrs}$. Fluorescent dye, CM$\mathrm{H}_{2}$ DCFDA (final concentration $10 \mu \mathrm{L}$ of $20 \mu \mathrm{M}$ ) was added to cells and incubated for 30 min in $\mathrm{CO}_{2}$ incubator to measure the intracellular ROS produced in these cells. After incubation, the cells were washed with cold phosphate buffered saline (PBS) and the amount of ROS was analysed by flow cytometry.

Gene expression analysis. NHDF were treated with RM191A $(0.5 \mathrm{mg} / \mathrm{mL})$ or vehicle control. Mature RNA was isolated using an RNA extraction kit (Qiagen) according to the manufacturer's instructions. RNA quality was determined using a spectrophotometer and was reverse transcribed using a cDNA conversion kit (Qiagen). The cDNA was used on the real-time $\mathrm{RT}^{2}$ Profiler PCR Arrays (QIAGEN, PAHS-065Y, PAHS-022Z and PAHS$162 Z$ ) in combination with $\mathrm{RT}^{2} \mathrm{SYBR} \circledast$ Green qPCR Mastermix (Qiagen). Fold changes in genes were calculated using delta delta $\mathrm{C}_{\mathrm{T}}$ method in data analysis web portal (http://www.qiagen.com/geneglobe). Each sample was assayed in replicates and each group was analysed twice. The heat map was generated using Morpheus software (Broad Institute). The $\mathrm{C}_{\mathrm{T}}$ cut-off was set to 36 .

Blood-brain-barrier transmission assay. hCMEC/D3 cell line derived from human brain endothelial cells were seeded onto membrane of $24 \mathrm{~mm}$ Transwells with $4 \mu \mathrm{m}$ pores (Corning) coated with $3 \%$ collagen at $4.5 \times 10^{5}$ cells/well and grown to confluence in RPMI 
$+10 \%$ FCS medium. RM191A was added to the top of the transwell at $0.02,0.04,0.08$ and $0.4 \mathrm{mg} / \mathrm{mL}$. After 2 and $6 \mathrm{hrs}$, media from top and bottom chambers of the transwells were collected and stored at $-20^{\circ} \mathrm{C}$ until further analysis. The media was then analysed by HPLC (Phenomenex Luna HILIC Analytical Column $3 \mu \mathrm{m}, 2$ x 100 mm, mobile phase: $85 / 15 \mathrm{ACN} / \mathrm{NH}_{4}$ formate buffer (0.1M, $\left.\mathrm{pH} 4.3\right)$ ).

UV exposure and RM191A treatment in skin explants. All experiments were performed according to procedures approved by University of Sydney Human Ethics Committee. Human skin explants were obtained with consent from patients undergoing elective surgery. The protocol for obtaining skin explants and for their use to examine photoprotective effects of test agents was described in Song et al., with some minor changes (33). In brief, skin removed at elective surgery was cleaned, subcutaneous fat removed and cut into pieces to produce multiple pieces approx. 4-6 $\mathrm{mm} \times 4-6 \mathrm{~mm}$, with each explant placed in one well of a 96 well plate in RPMI 1640 media containing 10\% FCS. Skin explants in triplicate were used for each treatment point. The DNA damage was analysed after $3 \mathrm{hrs}$ incubation period.

Skin was subjected to solar simulated UV-radiation, as previously described $(33,34)$. The spectral output of this solar simulator compared with sunlight is shown in Fig. S3A. Treatments, as indicated below, were applied to the epidermal surface of the explant. Sham wells were treated in a similar manner to UV-exposed wells, including media changes and treatments, but were covered with foil and not exposed to UV. RM191A gel or the control gel was used with two protocols. In Protocol 1, 1.5 $\mu \mathrm{L}$ of RM191A or gel was applied to the surface of the explant 10-15 minutes prior to UV exposure, then again immediately after UV and then at $0.5,1.5$, and $2.5 \mathrm{hrs}$. In Protocol $2,1.5 \mu \mathrm{L}$ of RM191A or gel was applied to the surface of the explant immediately after UV exposure, then at 1 , $2,2.5 \mathrm{hrs}$. In addition, vehicle containing wells consisted of RPMI media with $10 \% \mathrm{v} / \mathrm{v}$ FCS and $0.1 \% \mathrm{v} / \mathrm{v}$ spectroscopic ethanol applied immediately after UV. The positive control treatment was 1,25 dihydroxyvitamin D3 (1,25D) (33), which was dissolved in spectroscopic grade ethanol at a final concentration of $1 \mathrm{nM}$ and $0.1 \% \mathrm{v} / \mathrm{v}$ ethanol in RPMI media with $10 \%$ v/v FCS. This was also applied immediately after UV only. Sham wells consisted of vehicle (containing ethanol $0.1 \%$ - immediately after UV exposure), 1,25D (applied immediately after UV exposure), Gel 1 (Protocol 1 only) and RM191A 1 (Protocol 1 only). There were insufficient explants to do sham wells of RM191A and gel with Protocol 2. UV-exposed wells consisted of vehicle, 1,25D, Gel 1, Gel 2 (Protocol 2 only), RM191A 1 and RM191A 2 (Protocol 2 only).

Animal experiments. All experiments were performed according to procedures approved by UNSW Animal Care and Ethics Committee (UNSW, Australia). Male C57BL/6J mice (Australian BioResources, Mossvale, NSW and Animal Resource Centre, Canning Vale, WA, Australia) were housed in the UNSW Biological Resource Centre at $21^{\circ} \mathrm{C} \pm 2$, with a $12 \mathrm{hrs} / 12 \mathrm{hrs}$ dark/light cycle and were fed standard chow diet.

RM191A short-term and long-term treatment. One day prior to the application of RM191A or gel, male mice were anaesthetised and hair on the dorsal surface was removed with a clipper. The shaved area was then cleaned with betadine solution, wiped with an alcohol swap and dried for a few seconds. The following day, the animals were briefly anaesthetised and $50 \mu \mathrm{L}$ of RM191A at different concentrations was applied topically. This step was repeated for 4 and 29 consecutive days for short-term and longterm treatment protocols, respectively. On the $4^{\text {th }}$ and $30^{\text {th }}$ day, the animals were 
euthanized, tissues were harvested, and flash frozen in liquid nitrogen. The overall health of the animals was monitored daily and weights were recorded daily until euthanized. For the short-term treatment protocol, the treatment groups consisted of gel and RM191A $(0.19,0.38,0.76,1.33$ and $1.9 \mathrm{~mL} / \mathrm{kg}$ body weight). For short-term treatment protocol, the groups consisted of no gel, gel and RM191A $(0.19 \mathrm{~mL} / \mathrm{kg}$ body weight).

Rotarod test. Motor coordination was assessed using the rotarod test as previously described (35). In short, mice were acclimatized to a rotarod for 3 days in three trials lasting $2 \mathrm{~min}$ each at a constant speed of $5 \mathrm{rpm}$. On the 4th day, the animals were subjected to three trials on the accelerating roller (4-40 rpm in $4 \mathrm{~min}$ ) and the time that the mice remained was recorded.

Rearing test. Mouse rearing test was performed as described previously (36). Briefly, the mouse was placed in a clean transparent cylinder (diameter: $12 \mathrm{~cm}$, height: $15 \mathrm{~cm}$ ) for 3 minutes and its forelimb activity while rearing against the wall of the arena was recorded.

EchoMRI. Body composition (fat mass, lean mass, and total body water) was measured by EchoMRI (EchoMRI-900, Mark Wainwright Analytical Centre, UNSW).

RM191A time point study. One day prior to the application of RM191A in mice, the animals were anaesthetised and hair on the dorsal surface was removed with a clipper. The shaved area was then cleaned with betadine solution, wiped with alcohol swap and dried for a few seconds. Next day, the animals were briefly anaesthetised and $50 \mu \mathrm{L}$ of RM191A in gel formulation (1.9 mL/kg body weight) was applied topically. The animals were euthanized at $15 \mathrm{~min}, 30 \mathrm{~min}, 1 \mathrm{hr}$ and $2 \mathrm{hrs}$ post-treatment and tissues were harvested. Untreated animals were used for $t=0$.

ICP-MS. About $100 \mathrm{mg}$ of tissue sample (50 $\mu \mathrm{L}$ in the case of plasma and urine) was transferred to a $10 \mathrm{~mL}$ polypropylene tube (Sarstedt), then $200 \mu \mathrm{L}$ of concentrated nitric acid $\left(\mathrm{HNO}_{3}\right)$ was added and incubated for $12 \mathrm{hrs}$ at room temp with occasional shaking. After $12 \mathrm{hrs}$, the tube was heated at $80^{\circ} \mathrm{C}$ moderately up to clearing ( $5 \mathrm{hrs}$ ) and cooled down to room temperature. Then $20 \mu \mathrm{L}$ of hydrogen peroxide was added, and the tube was again heated upto $80^{\circ} \mathrm{C}$ for $2 \mathrm{hrs}$. Next, the volume was made up to $10 \mathrm{~mL}$ with milliQ water. A blank standard was prepared in the same way without tissue samples. The samples were then analyzed for copper using ICP-MS (PerkinElmer Nexicon) at Mark Wainwright Analytical Centre, UNSW.

Ear edema model. TPA (12-O-tetradecanoylphorbol-13-acetate)-induced mouse ear oedema was generated according to a published protocol (37). Briefly, $6 \mu \mathrm{g}$ of TPA dissolved in $20 \mu \mathrm{L}$ acetone was applied to the left ear of a mouse. Acetone $(20 \mu \mathrm{L})$ was applied to the right ear as vehicle control. Both ears were pre-treated with $50 \mu \mathrm{L}$ of gel or RM191A $(21 \mu \mathrm{g} / \mathrm{mL}), 15$ minutes prior to TPA or acetone application. After $6 \mathrm{hrs}$, ear tissue was excised using a $5 \mathrm{~mm}$ biopsy punch and ear weight was measured. The ear samples were then fixed in $10 \%$ formalin.

Wound regeneration model. Wound healing protocol in mice was performed as described previously, with minor modifications (38). One day prior to wounding, the animals were anaesthetised and hair on the dorsal surface was removed with a clipper. The shaved area was then cleaned with betadine solution, wiped with an alcohol swab and dried for a few seconds. Next day, the animals were briefly anaesthetised, and a 
wound was created on the dorsal skin using a $10 \mathrm{~mm}$ biopsy punch. The picture of wound was captured, and the wound was covered with a semi-occlusive dressing (3M Tegaderm). Two days after the wounding procedure, $50 \mu \mathrm{L}$ of gel or RM191A $(21 \mu \mathrm{g} / \mathrm{mL})$ was applied to the wound area and the application was repeated every 2 days. Each animal was singly housed during the entire procedure. The pictures of wounds were captured every 2 days and wound area was analyzed using ImageJ software.

Hematoxylin and eosin (H\&E) staining. After fixation in paraffin, samples were stained with $0.1 \%$ Hematoxylin for 10 min, rinsed with deionised $\mathrm{H}_{2} \mathrm{O}$, stained with Scott's blue solution for $1 \mathrm{~min}$ and then washed with deionised $\mathrm{H}_{2} \mathrm{O}$. The sections were then dipped in Eosin for $3 \mathrm{~min}$, dehydrated through alcohol and cleared in xylene. The slides were mounted with DPX and imaged using a Zeiss Axioscan Z1 slide scanner (University of Sydney).

Immunohistochemistry. Three or 24 hours after irradiation, the explants were fixed, embedded in paraffin and sectioned before being deparaffinized and rehydrated for staining. Antigen retrieval was achieved with $10 \mathrm{mM}$ citrate buffer. These sections were then stained as described for cyclobutane pyrimidine dimers (CPD), oxidative DNA damage in the form of 8-oxo-guanine (8-OxoG) and nitrosative DNA damage in the form of 8-nitro-guanine (8NGO) (33). Isotype controls were performed (without primary antibody). Immunohistochemistry was carried out and analysed using the Metamorph image analysis program as previously described (33), except that the results were expressed as mean pixel intensity - mean gray value in arbitrary units (34). In addition to analysing nuclear staining in the epidermis, for 8-oxoG and 8NGO, a separate analysis was performed on the upper layer of the dermis, where there were reasonable numbers of cells visible.

Statistics. Data are presented as mean \pm SEM. Statistical significance was performed using Student's t test or ANOVA with Tukey's post hoc test. Statistical tests were performed using GraphPad Prism software. P values of less than 0.05 were considered statistically significant.

\section{RESULTS}

\section{Synthesis and characterization of RM191A}

Synthesis of RM191A yielded a dark blue-green liquid which contains $11.8 \%$ copper (Fig. $1 \mathrm{~A}$, Table 1). RM191A was a highly polar complex that is completely insoluble in non-polar solvents. Although the UV-visible absorption spectra of RM191A was similar to that of CuEDTA complex (Fig. S1A), RM191A exhibited an intense fluorescence emission peak at $440 \mathrm{~nm}$ (Fig. 1B). FTIR spectra of RM191A showed absorbances characteristic of amino and carboxylic acid functionalities (Fig. S1B). This information combined with the elemental analysis indicated that RM191A is a copper-amino acid coordination complex.

To delineate the structure further, analysis via cryo-TEM was performed in which RM191A showed unexpected black dots of about $20-50 \mathrm{~nm}$ in diameter in comparison with a blank sample, strongly suggesting the presence of large copper-containing complexes in this sample (Fig. 1C). This conclusion was also supported by NMN diffusion ordered spectroscopy (DOSY), in which the compound exhibited a large apparent increase in the 
chelate hydrodynamic radii suggesting that the proton signals seen in the ${ }^{1} \mathrm{H}$ NMR of the copper chelate complex belong to a species that is oligomeric (Table 2, Fig. S1C). The hydrodynamic radius of $\mathrm{Cu}$ species in RM191A appeared to be at least $4.67 \AA$ or a diameter of nearly $1 \mathrm{~nm}$ compared to $3.0 \AA$ radius $(0.6 \mathrm{~nm}$ diameter $)$ for a standard $\mathrm{Zn}$ EDTA complex. X-ray diffraction of crystalline RM191A showed a hydrated copperpolyglycine coordination complex consisting of two copper atoms with square planar and pyramidal geometry (Fig. 1D, S1D). Diffusion pulsed voltammetry confirmed the presence of both $\mathrm{Cu}^{2+}$ and $\mathrm{Cu}^{3+}$ ions in RM191A (Fig. 1E, S1E).

\section{RM191A has potent antioxidant and anti-inflammatory properties}

The interesting similarity of RM191A to the dimeric structure of SOD1 and presence of unique $\mathrm{Cu}^{2+}-\mathrm{Cu}^{3+}$ dipole led us to postulate that RM191A would be a highly efficient free radical scavenger which could act in a similar manner to SOD. To prove our hypothesis, we measured and compared the superoxide scavenging activities of both bovine SOD and RM191A using a well-established assay (30). The results showed that at $20 \mu \mathrm{M}$ concentration, RM191A was 10 times more effective at neutralising superoxide free radicals than SOD (Fig. 2A). With increasing concentration, the activity of RM191A exceeded that of SOD by 30 times.

Next, we decided to test the bioactivity of RM191A in cells. For all subsequent experiments, RM191A was dissolved in a hydrogel (Gel). Upon treatment of N27 cells, an immortalized rat dopaminergic neuronal cell line (39), with different concentrations of RM191A and measuring the percentage of live cells by flow cytometry or MTT assay, the $\mathrm{LD}_{50}$ of RM191A was observed to be $210 \mu \mathrm{g} / \mathrm{mL}$ (Fig. 2B, S2B). Similarly, LD L $_{50}$ of RM191A for human umbilical vein endothelial cells (HUVEC) was found to be $210 \mu \mathrm{g} / \mathrm{mL}$ (Fig. S2C). In order to determine if RM191A could protect cells from ROS-mediated oxidative stress, $\mathrm{N} 27$ cells were first exposed to $200 \mu \mathrm{M}$ hydrogen peroxide for 30 minutes and then treated with $21 \mu \mathrm{g} / \mathrm{mL}$ RM191A (gel as control) for $4 \mathrm{hrs}$. RM191A treatment increased the viability of cells by $24 \%$, when measured by flow cytometry, compared to the control (Fig. $2 \mathrm{C}$ ).

ROS are known to mediate inflammatory responses induced by a variety of stimuli including lipopolysaccharide (LPS) $(40,41)$. Treatment of macrophage-like RAW 264.7 cells with SOD decreases LPS-induced ROS generation and upregulation of several inflammatory genes $(41,42)$. To investigate if RM191A has similar effects, at first, we determined its toxicity in RAW 264.7 cells using flow cytometry and MTT assay. The LD 50 of RM191A was $85 \mu \mathrm{g} / \mathrm{mL}$ in both assays (Fig. 2D, S2D). Next, RAW 264.7 cells were stimulated with LPS $(10 \mathrm{ng} / \mathrm{mL})$ and then treated with RM191A or gel only. The amount of ROS was measured by flow cytometry. LPS stimulation increased the ROS by $42 \%$, however, treatment with RM191A decreased ROS levels to $36 \%$ (Fig. 2E). Given this data, we were curious to understand RM191A's ability to affect oxidative stress and inflammatory pathways. To investigate this, adult normal human dermal fibroblasts (NHDF) were treated with RM191A and changes in gene expression compared to control were determined using PCR arrays. Toxicity analysis demonstrated that RM191A was well-tolearetd by NHDF, with no evident cell death upto a dose of $210 \mu \mathrm{g} / \mathrm{mL}$ (Fig. $2 \mathrm{~F}$ ). Although RM191A treatment did not change the expression of SODs in NHDF, the expression of several genes that confer cellular protection against oxidative stress were significantly upregulated (Fig. 2G, Table S1). Notably, heme oxygenase (HMOX1), heat shock protein (HSPA1A) and thioredoxin reductase (TXNRD1) expression increased by 
67, 7 and 5-fold respectively in RM191A-treated NHDF compared to the control. Amongst the inflammatory genes, CCL7, ACKR4, CXCR6 and CMKLR1 were downregulated, while the expression of CCL26, CXCL8 and TLR4 were upregulated in RM191A-treated NHDF (Fig. $2 \mathrm{H}$, Table S2). These small changes in chemokines may be due to the fact that in basal condition, the inflammatrory genes are not upregulated in NHDF and therefore the protective effects of RM191A were not obvious. Repeating the experiment where the NHDF are subjected to oxidative stress by external stimuli would be ideal to demonstrate the anti-inflamamtory effects of RM191A. Since inflammation also contributes to pain (43), we measured the effects of RM191A on pain-associated genes. Several key biomarkers of pain, for example, IL-18, CCL2, serotonin receptor (HTR2A) and ion channel (TRPV1) were downregulated in NHDF upon RM191A treatment (Fig. 2I, Table S3).

\section{RM191A protects skin against UV-induced oxidative stress and DNA damage}

Exposure of skin to UV radiation induces direct DNA damage such as generation of cyclobutene pyrimidine dimers (CPD), as well as oxidative stress via a dramatic increase in ROS (44). Such an increase results in characteristic DNA damage, for example, oxidative DNA damage in the form of 8-oxo-guanine (8-oxoG) and nitrosative DNA damage in the form of 8-nitroguanine (8NGO) (45). If these DNA lesions are inadequately repaired, mutations may occur and may lead to the development of skin tumours (45). We wanted to determine whether RM191A, when applied topically to ex vivo human skin, reduced UV-induced DNA damage.

Human skin was either pre-treated with RM191A (RM191A 1), followed by exposure to UV radiation, or treated with RM191A (RM191A 2), immediately after UV exposure. In both cases, RM191A treatment post-UV exposure was repeated every 30 minutes for 3 hrs incubation period. The same treatment protocols were also followed for gel (Gel). An active form of vitamin $D-1,25$-dihydroxyvitamin D3 $(1,25 D)$, was used as a positive control in these experiments as it has previously been shown that topical application of $1,25 \mathrm{D}$ reduces $U V$-induced DNA damage in human skin cells, human skin explants and human subjects, and reduces UV-induced skin tumours in mice $(46,47)$. Ethanol (Vehicle) was used as a control for $1,25 \mathrm{D}$ treatment. Staining for CPD, was virtually absent in the isotype control, and the intensity of nuclear staining was low in the sham exposed explants, indicating very few CPDs (Fig. S3B). This was expected, since exposure to UV was the major source of the energy required to produce CPD. Exposure to UV significantly increased CPD in UV-vehicle or UV-gel groups compared with their respective sham controls (compare Fig. 3A and Fig. S3B). Treatment of UV-exposed explants with 1,25D or RM191A (RM191A 2) decreased CPD by 30\% compared to their respective UVexposed controls (Fig. 3A). When pre-treated with RM191A (RM191A 1), CPD decreased by $37 \%$ compared to its control (Fig. $3 \mathrm{~A}$ ).

The intensity of nuclear 8-oxoG staining was moderate in the sham exposed explants treated with vehicle or 1,25D (Fig. S3C) due to the fact that culture of the explants engendered some oxidative stress. Markedly increased cytoplasmic staining was seen in explants which were sham exposed and treated with either gel or RM191A (Fig. S3C). Because of this high level of cytoplasmic staining, which was also observed in UV exposed explants, for the analysis, two separate masks (cytoplasmic and nuclear) were created using the Metamorph image analysis program and only the nuclear staining was imaged, so as not to include this strong background, non-specific cytoplasmic stain. Exposure to UV significantly increased nuclear 8-oxoG in both the UV-vehicle and UV-gel groups 
compared with their respective sham controls (compare Fig. S3C and Fig. 3B). Treatment of UV-exposed explants with 1,25D decreased nuclear 8 -oxoG by $27 \%$ compared to their UV-exposed controls. Treatment with RM191A (RM191A 2) was found to decrease 8oxoG levels by $33 \%$, and the RM191A pre-treated group (RM191A 1) was found to have $55 \%$ less 8-oxoG, when compared to UV-exposed controls (Fig. 3B). Interestingly, oxidative DNA damage in the nuclei of epidermal cells was lower in RM191A-treated sham explants compared to gel-treated sham wells, indicating that RM191A was able to reduce even base-level oxidative damage. There were far fewer cells in the dermis of the explants, but an analysis was performed on the intensity of staining in the nuclei of cells of the upper dermis. Nuclear staining for 8-oxoG was overall lower in the dermis of sham exposed explants than in UV-exposed explants, but it was not negligible (Fig. 3B). Pre-treatment of sham explants with RM191A significantly reduced 8-oxoG staining. Nuclear stain for 8oxOG was significantly increased in the dermis in vehicle and gel treated UV-exposed explants, compared with sham exposed controls, though the fold increase with UV was not as great as seen in the epidermis, probably reflecting reduced penetration of UV into the dermis. Nevertheless, as shown in Figure 3B, each of the active treatments significantly reduced 8-oxoG in the dermis.

Similar to 8-oxoG staining, exposure to UV significantly increased nuclear 8NGO staining in UV-vehicle and UV-gel groups, in both the epidermis and dermis, compared with their respective sham controls (compare Fig. S3D and Fig. $3 \mathrm{C}$ ). As shown in Figure $3 \mathrm{C}$, treatment of UV-exposed explants with 1,25D or with RM191A using either protocol significantly decreased 8NGO compared with their UV-exposed controls. Again, pretreatment of UV-exposed explants with RM191A was more effective at reducing nitrosative DNA damage than RM191A post-treatment.

\section{RM191A is non-toxic and readily bioavailable in mice}

After determining the biological activities of RM191A in cells and skin explants, we sought to determine if these effects can translate in vivo. Firstly, we used a mouse model to test if RM191A has any toxicity in animals. The dorsal surfaces of 12 week old male mice were shaved and $50 \mu \mathrm{L}$ of RM191A at different doses $(0.19-1.9 \mathrm{~mL} / \mathrm{kg}$ body weight) was applied topically daily for 4 days. We found that there were no significant changes in the body weight or tissue weights of these animals compared to vehicle control (gel only) after 4 days of topical treatment (Fig. 4A, Table S4), implying that short-term treatment of RM191A is well tolerated in mice up to a concentration of $1.9 \mathrm{~mL} / \mathrm{kg}$ body weight.

Next, we studied if RM191A was also well tolerated over long-term treatment. As previously, the dorsal area of 8 week old mice was shaved, and the animals were either left untreated or treated topically daily with $50 \mu \mathrm{L}$ of gel (control) or RM191A at $0.19 \mathrm{~mL} / \mathrm{kg}$ body weight for 29 days. No significant changes in body weight, water intake or food intake were observed between the three groups (Fig. 4B, S4A). The fat content, lean mass and water content, as measured using EchoMRI, were similar among these three groups (Fig. S4B). After confirming that RM191A treatment did not have any adverse impact on the general health of mice, we explored if its exposure altered the behaviour of mice. In a standard rotarod test, the animals from all three groups performed equally well, indicating no significant impact on the motor coordination in mice (Fig. S4C). Both gel and RM191Atreated groups exhibited higher spontaneous rearing behaviour compared to the untreated group (Fig. S4D). Although this increase was not significant, it implied that the gel might improve exploratory behaviour of mice. In order to confirm that there was no overt toxicity 
in the tissue of various organs, wet tissue weights were measured, and no differences between treated and control groups were observed (Table S5). Furthermore, histological analyses of these tissues by hematoxylin and eosin (H\&E) staining showed normal morphology across all groups (Fig. S4E).

Following up on the results from the toxicity studies and skin explant experiment, we further explored RM191A's ability to penetrate through the skin into the body. The primary goal was to determine whether or not RM191A remained on the skin where it could be washed away, or if it penetrated through the skin into the blood. To gain these insights, we applied $50 \mu \mathrm{L}$ of RM191A (1.9 mL/kg body weight) topically to the shaved dorsal surfaces of 8 week old mice and measured total copper content in different animal tissues at different time points using ICP-MS. As expected, the amount of copper in the skin steadily increased within 15 minutes and stayed steady upto 2 hrs following RM191A treatment (Fig. 4C). There was also a significant increase in copper levels in internal tissues, including liver, lymph nodes and kideney (Fig. 4D, 4E, S4F), which implied that topically applied RM191A was able to penetrate through the skin layers and into the bloodstream (Figure S4G). The ICP-MS results demonstrated that the copper in RM191A follows the common mammalian metabolic route, with most of the copper being metabolized by the liver, the remainder by the kidneys and was excreted within one hour via the faeces (Fig. 4F) and urine (Fig. S4H). Moreover, the copper was cleared from the body within $24 \mathrm{hrs}$ as its levels in tissues and blood collected $24 \mathrm{hrs}$ after RM191A application reduced to the same level as the control group at this time point (Table 3 ).

The changes in brain copper levels indicated that RM191A might be able to cross the blood-brain-barrier (Fig. S4I). This was further investigated using a standard in vitro model for human blood-brain-barrier transmission which demonstrated that $50.79 \%$ of RM191A at $0.4 \mathrm{mg} / \mathrm{mL}$ concentration crossed the BBB in $2 \mathrm{hrs}$, and $95.65 \%$ crossed the BBB within $6 \mathrm{hrs}$ (Fig. S4J).

\section{RM191A attenuates inflammation and improves wound healing in mice}

Our previous in vitro data demonstrated that RM191A exhibits anti-inflammatory activity via suppression of ROS overproduction and the beneficial modulation of various signalling pathways. To test this in vivo, we employed a TPA (12-O-tetradecanoylphorbol-13acetate)-induced mouse ear edema model to evaluate the anti-inflammatory activity of RM191A in mice (48). TPA treatment doubled the ear weight after $6 \mathrm{hrs}$ when compared to vehicle (acetone)-treated control (Fig. 5A). Pre-treatment with RM191A (50 $\mu \mathrm{L}$ of 21 $\mu \mathrm{g} / \mathrm{mL}$ ) reduced the ear weight by $83 \%$ compared to gel and TPA-treated control. H\&E staining of ear cross-sections showed increased ear thickening and leukocyte infiltration in TPA and gel-treated group, which was significantly attenuated in the RM191A pretreated group.

Finally, we tested the effect of RM191A in wound regeneration in mice. A circular wound of $10 \mathrm{~mm}$ diameter was created on the dorsal surfaces of 12 week old male mice, after which $50 \mu \mathrm{L}$ of RM191A ( $21 \mu \mathrm{g} / \mathrm{mL}$ ) or gel alone was topically applied every 2 days to the wound area. Only two days after the start of RM191A treatment, 31\% wound regeneration was observed in RM191A-treated group compared to only $12 \%$ wound closure in the control group (Fig. 5B). After 12 days, $93 \%$ of the skin was regenerated in the RM191Atreated animals, whereas $77 \%$ of the wound area was healed in gel-treated mice. H\&E 
staining of the wound areas at 12 days showed regeneration of both epidermis and dermis layers in RM191A-treated group, whereas incomplete restoration of skin layers in the geltreated group.

\section{DISCUSSION}

Native SODs are protective against various oxidative stress-mediated skin disorders. This fact has invoked interest in SOD mimetics for therapeutic applications. Among the various classes of SOD mimetics, only manganese porphyrin complexes have shown promise in clinical trials $(49,50)$. This is likely due to the fact that unlike previously reported iron and copper coordination complexes, manganese-based SOD mimetics have lower toxicity, higher activity and increased stability. RM191A is the next generation copper-based SOD mimetic that is highly stable and whose activity surpasses native SOD's abilities to scavenge free radicals, and exceeds most of the manganese-based SOD-mimetics. There are several reasons for RM191A's high SOD-like activity. Each molecule of RM191A can react with three $\mathrm{O}_{2}{ }^{-}$ions while reducing $\mathrm{Cu}^{2+}-\mathrm{Cu}^{3+}$ dipole to $\mathrm{Cu}^{+}-\mathrm{Cu}^{+}$, whereas $\mathrm{Mn}^{2+}$-based SOD-mimetics can react with one $\mathrm{O}_{2}^{-}$ion (Fig. S2E). Moreover, the reduction potential indicates that its $\mathrm{k}_{\text {cat }}$ for $\mathrm{Cu}^{3+} / \mathrm{Cu}^{2+}$ reduction is likely to be higher than that of $\mathrm{Cu}^{2+} / \mathrm{Cu}^{+}$ reduction, although this entails further investigation. Moreover, in cells RM191A can upregulate various antioxidant genes, such as heme oxygenase, heat shock protein and thioredoxin reductase, which can further boost its antioxidant capacity.

Despite its water solubility, RM191A was able to penetrate the skin and distribute into different internal organs. Our toxicity results demonstrated that RM191A is well-tolerated in animals. A $26 \mathrm{~g}$ mouse can tolerate up to $50 \mu \mathrm{L}$ of topical RM191A with no side effects. This is equivalent to $144 \mathrm{~mL}$ applied to the skin of a $75 \mathrm{~kg}$ human. We have further found that RM191A is stable in light and heat up to $30^{\circ} \mathrm{C}$ for more than 12 months and that the RM191A remains active and safe in a topical hydrogel formulation over this timeframe. As far as we are aware, all previous work identifying the biological activities of copper, including its molecular mechanisms, its role in oxidative stress, and its homeostasis, specifically relate to $\mathrm{Cu}^{2+}$ as it would normally be present in the body (51-54). Therefore, the biological activity of a $\mathrm{Cu}^{3+}$ as present in RM191A is reported here for the first time.

Topical RM191A showed promise as a photoprotective agent in human skin and was at least as active as $1,25 \mathrm{D}$, generally acknowledged for its photoprotective properties $(34,45$ 48). One of the obvious reasons for this is the reduction of ROS and RNS by RM191A, although their levels were not directly tested in the explants. This may even explain the lower CPD after $3 \mathrm{hrs}$, since ROS and RNS damage DNA repair enzymes and thus inhibit DNA repair (55-57). RM191A may reduce DNA damage by other mechanisms, such as increasing energy available for DNA repair, upregulating DNA repair enzymes or enhancing mitochondrial repair (34). However, to verify this and other results it will be necessary to repeat this study in explants prepared from a range of donors with different skin types. Inadequately repaired DNA damage is a key factor leading to mutations and then to UV-induced skin tumours as well as photo-aging (45). It would be worth testing whether RM191A application in a chronic UV-exposure model reduces skin tumours and/or photo-aging in the UV exposed areas.

The topical application of the RM191A demonstrated remarkable inhibition of inflammation in the TPA mouse ear model, which has significant implications for human use for the treatment of chronic inflammatory-driven diseases including skin conditions like psoriasis 
(58). Similar to LPS, ROS generated by TPA can activate the inflammatory cascade (59), which we have found is significantly inhibited by RM191A. The direct involvement of RM191A in downregulating inflammatory pathways was corroborated by gene expression analysis in NHDF, where RM191A inhibited the expression of many genes reported to be involved in skin inflammation. It is possible that anti-inflammatory properties of RM191A are partly mediated by its ROS-scavaging activitiy. Although RM191A treatment had marked improvement in the healing rate of large, full-thickness excisional wounds in mice, the mechanism is not very clear to us as wound healing response is known to be orchestrated by retrograde inflammation and ROS generation $(60,61)$. It is possible that RM191A facilitates the formation of new tissues by upregulating key repair genes and also reduces unwanted inflammation during the healing process. Nonetheless, it will be interesting to investigate how RM191A performs in chronic non-healing wounds and diabetic ulcers. RM191A's ability to reduce oxidative stress, inflammation and modulate pain-asscoiated biomarkers indicate that RM191A may have the potential to attenuate chronic pain. Although measurement of pain was beyond the scope of this study, RM191A is currently the subject of a human clinical trial for the treatment of neuropathic pain (HREC/16/HAWKE/483).

In addition to demonstrating robust antioxidant and anti-inflammatory properties, RM191A might also facilitate the incorporation of copper into SOD1 and SOD3, ceruloplasmin and tissue repair enzymes - lysyl oxidase and elastase, which in turn can accelerate healing and inhibit inflammation. A similar mechanism has been proposed for Cu-ATSM, which is currently in clinical trial for motor neurone disease (MND) $(62,63)$. It may also be that RM191A is protective of mitochondria by eliminating ROS before it can cause mitochondrial damage, effectively preserving normal cell signalling and maintaining the integrity of the mitochondria.

Finally, oxidative stress has been linked to a multitude of human diseases and conditions, including aging, bipolar disorder, cancer, chronic morphine intolerance, diabetes, eye diseases, fibromyalgia, ischemia, pain, radiation injury, reperfusion-related injuries - for example heart attack, stroke, and organ dysfunction; as well as neurodegenerative disorders like Alzheimer's, Parkinson's, MND, multiple sclerosis and epilepsy, to mention only a few (64). RM191A's ability to almost instantly neutralize ROS, simultaneously diminish or eliminate the inflammatory response and easily penetrate into the brain, sets it apart as a new therapeutic and means that it likely has significant benefit in the treatment of a wide variety of human diseases/conditions.

\section{CONCLUSION}

RM191A is a novel small molecule SOD mimetic that demonstrated significant SOD-like antioxidant and anti-inflammatory activities. These combined actions are likely the result of its unique, stable $\mathrm{Cu}^{2+}-\mathrm{Cu}^{3+}$ dipole. RM191A exhibited protective effects towards wide range of cells against oxidative stress by suppressing ROS levels and via modulating the expression of several key genes associated with oxidative stress and inflammation. The topical application of RM191A beneficially and significantly reduced three types of UVinduced DNA damage in human skin explants in the epidermis and some in dermis. This reduction in DNA damage was similar to that produced by a well-established photoprotective agent, 1,25D. RM191A easily penetrated the skin layers and was readily distributed systemically throughout the body in mice. Both short-term and long-term dosing of RM191A did not exhibit any adverse effects in mice. It's topical application significantly 
reduced TPA-induced ear inflammation and accelerated excisional wound repair in mice. Therefore, RM191A is new class of SOD mimetic which exhibited beneficial effects in various skin disorders.

\section{CONFLICTS OF INTEREST}

LC is the Director and co-founder of RR MedSciences that holds patents for the synthesis and application of RM191A. Research studies at Macquarie University, University of New South Wales and University of Sydney were funded by RR MedSciences.

\section{ACKNOWLEDGEMENTS}

This paper is dedicated to our co-author Dr. Alistair J. Laos, a brilliant young mind and a promising scientist, whom we lost too soon. The mouse experiments were supported by NSW-Government Tech Voucher Grant awarded to RR MedSciences and AD.

\section{REFERENCES}

1. D'Orazio, J., Jarrett, S., Amaro-Ortiz, A., and Scott, T. (2013) UV radiation and the skin. Int J Mol Sci 14, 12222-12248

2. Hollestein, L. M., and Nijsten, T. (2014) An insight into the global burden of skin diseases. J Invest Dermatol 134, 1499-1501

3. Basra, M. K., and Shahrukh, M. (2009) Burden of skin diseases. Expert Rev Pharmacoecon Outcomes Res 9, 271-283

4. Addor, F. A. S. (2018) Beyond photoaging: additional factors involved in the process of skin aging. Clin Cosmet Investig Dermatol 11, 437-443

5. Rinnerthaler, M., Bischof, J., Streubel, M. K., Trost, A., and Richter, K. (2015) Oxidative stress in aging human skin. Biomolecules 5, 545-589

6. Bickers, D. R., and Athar, M. (2006) Oxidative stress in the pathogenesis of skin disease. J Invest Dermatol 126, 2565-2575

7. Finkel, T., and Holbrook, N. J. (2000) Oxidants, oxidative stress and the biology of ageing. Nature 408, 239-247

8. Schieber, M., and Chandel, N. S. (2014) ROS function in redox signaling and oxidative stress. Curr Biol 24, R453-462

9. Di Meo, S., Reed, T. T., Venditti, P., and Victor, V. M. (2016) Role of ROS and RNS Sources in Physiological and Pathological Conditions. Oxid Med Cell Longev 2016, 1245049

10. Addor, F. A. S. (2017) Antioxidants in dermatology. An Bras Dermatol 92, 356362

11. Reuter, S., Gupta, S. C., Chaturvedi, M. M., and Aggarwal, B. B. (2010) Oxidative stress, inflammation, and cancer: how are they linked? Free radical biology \&amp; medicine 49, 1603-1616

12. Alvarez-Arellano, L., Gonzalez-Garcia, N., Salazar-Garcia, M., and Corona, J. C. (2020) Antioxidants as a Potential Target against Inflammation and Oxidative Stress in Attention-Deficit/Hyperactivity Disorder. Antioxidants (Basel) 9

13. Biswas, S. K. (2016) Does the Interdependence between Oxidative Stress and Inflammation Explain the Antioxidant Paradox? Oxidative medicine and cellular longevity 2016, 5698931 
14. Hakim, J. (1993) [Reactive oxygen species and inflammation]. Comptes rendus des seances de la Societe de biologie et de ses filiales 187, 286-295

15. Fridovich, I. (1975) Superoxide dismutases. Annu Rev Biochem 44, 147-159

16. Chen, L., Hu, J. Y., and Wang, S. Q. (2012) The role of antioxidants in photoprotection: a critical review. J Am Acad Dermatol 67, 1013-1024

17. Le Quéré, S., Lacan, D., Lemaire, B., Carillon, J., Schmitt, K.,. (2014) The role of superoxide dismutase (SOD) in skin disorders. Nutrafoods 13, 13-27

18. Iuchi, Y., Roy, D., Okada, F., Kibe, N., Tsunoda, S., Suzuki, S., Takahashi, M., Yokoyama, H., Yoshitake, J., Kondo, S., and Fujii, J. (2010) Spontaneous skin damage and delayed wound healing in SOD1-deficient mice. Mol Cell Biochem 341, 181-194

19. Yasui, K., and Baba, A. (2006) Therapeutic potential of superoxide dismutase (SOD) for resolution of inflammation. Inflamm Res 55, 359-363

20. McCord, J. M., and Edeas, M. A. (2005) SOD, oxidative stress and human pathologies: a brief history and a future vision. Biomed Pharmacother 59, 139142

21. Perry, J. J., Shin, D. S., Getzoff, E. D., and Tainer, J. A. (2010) The structural biochemistry of the superoxide dismutases. Biochimica et biophysica acta 1804, 245-262

22. Hart, P. J., Balbirnie, M. M., Ogihara, N. L., Nersissian, A. M., Weiss, M. S., Valentine, J. S., and Eisenberg, D. (1999) A structure-based mechanism for copper-zinc superoxide dismutase. Biochemistry 38, 2167-2178

23. Tainer, J. A., Getzoff, E. D., Richardson, J. S., and Richardson, D. C. (1983) Structure and mechanism of copper, zinc superoxide dismutase. Nature 306, 284-287

24. Lippard, K. G. S. a. S. J. (1982) Chemistry of the imidazolate-bridged bimetallic center in the $\mathrm{Cu}-\mathrm{Zn}$ superoxide dismutase and its model compounds. Accounts of Chemical Research 15, 318-326

25. Salvemini, D., Riley, D. P., and Cuzzocrea, S. (2002) SOD mimetics are coming of age. Nat Rev Drug Discov 1, 367-374

26. Stover, K., Fukuyama, T., Young, A. T., Daniele, M. A., Oberley, R., Crapo, J. D., and Baumer, W. (2016) Topically applied manganese-porphyrins BMX-001 and BMX-010 display a significant anti-inflammatory response in a mouse model of allergic dermatitis. Arch Dermatol Res 308, 711-721

27. Bonetta, R. (2018) Potential Therapeutic Applications of MnSODs and SODMimetics. Chemistry (Weinheim an der Bergstrasse, Germany) 24, 5032-5041

28. Novotna, R., Travnicek, Z., and Herchel, R. (2012) SOD-Mimic Cu(II) Dimeric Complexes Involving Kinetin and Its Derivative: Preparation and Characterization. Bioinorg Chem Appl 2012, 704329

29. Liakopoulou-Kyriakides, M., Hadjispyrou, S., and Zarkadis, A. (1999) Cu(III)polypeptide complexes exhibiting SOD-like activity. Amino acids 16, 415-423

30. Beauchamp, C., and Fridovich, I. (1971) Superoxide dismutase: improved assays and an assay applicable to acrylamide gels. Anal Biochem 44, 276-287

31. Das, A., Huang, G. X., Bonkowski, M. S., Longchamp, A., Li, C., Schultz, M. B., Kim, L. J., Osborne, B., Joshi, S., Lu, Y., Trevino-Villarreal, J. H., Kang, M. J., Hung, T. T., Lee, B., Williams, E. O., Igarashi, M., Mitchell, J. R., Wu, L. E., Turner, N., Arany, Z., Guarente, L., and Sinclair, D. A. (2018) Impairment of an Endothelial NAD(+)-H2S Signaling Network Is a Reversible Cause of Vascular Aging. Cell 173, 74-89 e20

32. Sekhar, S., Sampath-Kumara, K. K., Niranjana, S. R., and Prakash, H. S. (2015) Attenuation of reactive oxygen/nitrogen species with suppression of inducible 
nitric oxide synthase expression in RAW 264.7 macrophages by bark extract of Buchanania lanzan. Pharmacogn Mag 11, 283-291

33. Song, E. J., Gordon-Thomson, C., Cole, L., Stern, H., Halliday, G. M., Damian, D. L., Reeve, V. E., and Mason, R. S. (2013) 1alpha,25-Dihydroxyvitamin D3 reduces several types of UV-induced DNA damage and contributes to photoprotection. J Steroid Biochem Mol Biol 136, 131-138

34. Rybchyn, M. S., De Silva, W. G. M., Sequeira, V. B., McCarthy, B. Y., Dilley, A. V., Dixon, K. M., Halliday, G. M., and Mason, R. S. (2018) Enhanced Repair of UV-Induced DNA Damage by 1,25-Dihydroxyvitamin D3 in Skin Is Linked to Pathways that Control Cellular Energy. J Invest Dermatol 138, 1146-1156

35. Mersmann, N., Tkachev, D., Jelinek, R., Roth, P. T., Mobius, W., Ruhwedel, T., Ruhle, S., Weber-Fahr, W., Sartorius, A., and Klugmann, M. (2011) Aspartoacylase-lacZ knockin mice: an engineered model of Canavan disease. PLoS One 6, e20336

36. Aguiar, A. S., Jr., Moreira, E. L., Hoeller, A. A., Oliveira, P. A., Cordova, F. M., Glaser, V., Walz, R., Cunha, R. A., Leal, R. B., Latini, A., and Prediger, R. D. (2013) Exercise attenuates levodopa-induced dyskinesia in 6-hydroxydopaminelesioned mice. Neuroscience 243, 46-53

37. Inoue, H., Mori, T., Shibata, S., and Koshihara, Y. (1989) Modulation by glycyrrhetinic acid derivatives of TPA-induced mouse ear oedema. $\mathrm{Br} \mathrm{J}$ Pharmacol 96, 204-210

38. Succar, J., Giatsidis, G., Yu, N., Hassan, K., Khouri, R., Jr., Gurish, M. F., Pejler, G., Abrink, M., and Orgill, D. P. (2019) Mouse Mast Cell Protease-4 Recruits Leukocytes in the Inflammatory Phase of Surgically Wounded Skin. Adv Wound Care (New Rochelle) 8, 469-475

39. Holmes, S., Abbassi, B., Su, C., Singh, M., and Cunningham, R. L. (2013) Oxidative stress defines the neuroprotective or neurotoxic properties of androgens in immortalized female rat dopaminergic neuronal cells. Endocrinology 154, 4281-4292

40. Hsu, H. Y., and Wen, M. H. (2002) Lipopolysaccharide-mediated reactive oxygen species and signal transduction in the regulation of interleukin-1 gene expression. J Biol Chem 277, 22131-22139

41. Lee, J. A., Song, H. Y., Ju, S. M., Lee, S. J., Kwon, H. J., Eum, W. S., Jang, S. H., Choi, S. Y., and Park, J. S. (2009) Differential regulation of inducible nitric oxide synthase and cyclooxygenase-2 expression by superoxide dismutase in lipopolysaccharide stimulated RAW 264.7 cells. Exp Mol Med 41, 629-637

42. Ferret, P. J., Soum, E., Negre, O., and Fradelizi, D. (2002) Auto-protective redox buffering systems in stimulated macrophages. BMC Immunol 3, 3

43. Ji, R. R., Chamessian, A., and Zhang, Y. Q. (2016) Pain regulation by nonneuronal cells and inflammation. Science 354, 572-577

44. Dunaway, S., Odin, R., Zhou, L., Ji, L., Zhang, Y., and Kadekaro, A. L. (2018) Natural Antioxidants: Multiple Mechanisms to Protect Skin From Solar Radiation. Front Pharmacol 9, 392

45. Mason, R. S., and Reichrath, J. (2013) Sunlight vitamin D and skin cancer. Anticancer Agents Med Chem 13, 83-97

46. Gupta, R., Dixon, K. M., Deo, S. S., Holliday, C. J., Slater, M., Halliday, G. M., Reeve, V. E., and Mason, R. S. (2007) Photoprotection by 1,25 dihydroxyvitamin D3 is associated with an increase in p53 and a decrease in nitric oxide products. J Invest Dermatol 127, 707-715

47. Dixon, K. M., Norman, A. W., Sequeira, V. B., Mohan, R., Rybchyn, M. S., Reeve, V. E., Halliday, G. M., and Mason, R. S. (2011) 1alpha,25(OH)(2)-vitamin 
$\mathrm{D}$ and a nongenomic vitamin $\mathrm{D}$ analogue inhibit ultraviolet radiation-induced skin carcinogenesis. Cancer Prev Res (Phila) 4, 1485-1494

48. Song, H. Y., Lee, J. A., Ju, S. M., Yoo, K. Y., Won, M. H., Kwon, H. J., Eum, W. S., Jang, S. H., Choi, S. Y., and Park, J. (2008) Topical transduction of superoxide dismutase mediated by HIV-1 Tat protein transduction domain ameliorates 12-O-tetradecanoylphorbol-13-acetate (TPA)-induced inflammation in mice. Biochem Pharmacol 75, 1348-1357

49. Batinic-Haberle, I., and Tome, M. E. (2019) Thiol regulation by Mn porphyrins, commonly known as SOD mimics. Redox Biol 25, 101139

50. Yulyana, Y., Tovmasyan, A., Ho, I. A., Sia, K. C., Newman, J. P., Ng, W. H., Guo, C. M., Hui, K. M., Batinic-Haberle, I., and Lam, P. Y. (2016) Redox-Active Mn Porphyrin-based Potent SOD Mimic, MnTnBuOE-2-PyP(5+), Enhances Carbenoxolone-Mediated TRAIL-Induced Apoptosis in Glioblastoma Multiforme. Stem Cell Rev Rep 12, 140-155

51. Arredondo, M., and Nunez, M. T. (2005) Iron and copper metabolism. Mol Aspects Med 26, 313-327

52. Daniel, K. G., Gupta, P., Harbach, R. H., Guida, W. C., and Dou, Q. P. (2004) Organic copper complexes as a new class of proteasome inhibitors and apoptosis inducers in human cancer cells. Biochem Pharmacol 67, 1139-1151

53. Puig, S., and Thiele, D. J. (2002) Molecular mechanisms of copper uptake and distribution. Curr Opin Chem Biol 6, 171-180

54. Uriu-Adams, J. Y., and Keen, C. L. (2005) Copper, oxidative stress, and human health. Mol Aspects Med 26, 268-298

55. Jaiswal, M., LaRusso, N. F., Burgart, L. J., and Gores, G. J. (2000) Inflammatory cytokines induce DNA damage and inhibit DNA repair in cholangiocarcinoma cells by a nitric oxide-dependent mechanism. Cancer Res 60, 184-190

56. Nguyen, T., Brunson, D., Crespi, C. L., Penman, B. W., Wishnok, J. S., and Tannenbaum, S. R. (1992) DNA damage and mutation in human cells exposed to nitric oxide in vitro. Proc Natl Acad Sci U S A 89, 3030-3034

57. Bau, D. T. G., J.R.; Jan, K.Y. (2001) Nitric oxide is involved in arsenite inhibition of pyrimidine dimer excision. Carcinogenesis 22, 709-716

58. Schon, M. P., and Boehncke, W. H. (2005) Psoriasis. N Engl J Med 352, 18991912

59. Huang, R., Zhao, L., Chen, H., Yin, R. H., Li, C. Y., Zhan, Y. Q., Zhang, J. H., Ge, C. H., Yu, M., and Yang, X. M. (2014) Megakaryocytic differentiation of K562 cells induced by PMA reduced the activity of respiratory chain complex IV. PLoS One 9, e96246

60. Koh, T. J., and DiPietro, L. A. (2011) Inflammation and wound healing: the role of the macrophage. Expert Rev Mol Med 13, e23

61. Dunnill, C., Patton, T., Brennan, J., Barrett, J., Dryden, M., Cooke, J., Leaper, D., and Georgopoulos, N. T. (2017) Reactive oxygen species (ROS) and wound healing: the functional role of ROS and emerging ROS-modulating technologies for augmentation of the healing process. Int Wound $J 14,89-96$

62. https://www.mndaust.asn.au/Discover-our-research/Latest-research/Clinicaltrials/Copper-ATSM-Clinical-Trial.aspx.

63. Roberts, B. R., Lim, N. K., McAllum, E. J., Donnelly, P. S., Hare, D. J., Doble, P. A., Turner, B. J., Price, K. A., Lim, S. C., Paterson, B. M., Hickey, J. L., Rhoads, T. W., Williams, J. R., Kanninen, K. M., Hung, L. W., Liddell, J. R., Grubman, A., Monty, J. F., Llanos, R. M., Kramer, D. R., Mercer, J. F., Bush, A. I., Masters, C. L., Duce, J. A., Li, Q. X., Beckman, J. S., Barnham, K. J., White, A. R., and Crouch, P. J. (2014) Oral treatment with $\mathrm{Cu}(\mathrm{II})(\mathrm{atsm})$ increases mutant SOD1 in 
bioRxiv preprint doi: https://doi.org/10.1101/2020.05.10.086694; this version posted May 11,2020 . The copyright holder for this preprint (which

was not certified by peer review) is the author/funder, who has granted bioRxiv a license to display the preprint in perpetuity. It is made available under aCC-BY-NC-ND 4.0 International license.

vivo but protects motor neurons and improves the phenotype of a transgenic mouse model of amyotrophic lateral sclerosis. J Neurosci 34, 8021-8031

64. Batinic-Haberle, I., Reboucas, J. S., and Spasojevic, I. (2010) Superoxide dismutase mimics: chemistry, pharmacology, and therapeutic potential.

Antioxidants \&amp; redox signaling 13, 877-918 


\section{TABLES}

Table 1: Elemental analysis of RM191A

\begin{tabular}{|l|l|l|l|l|l|l|}
\hline Element & $\mathbf{C u}$ & $\mathbf{C}$ & $\mathbf{H}$ & $\mathbf{N}$ & $\mathbf{N a}$ & $\mathbf{O}$ \\
\hline$\%$ & 11.8 & 27.46 & 4.45 & 7.06 & 12.0 & 37.23 \\
\hline
\end{tabular}

Table 2: DOSY analysis of Zinc-EDTA and RM191A complex

\begin{tabular}{|c|c|c|c|c|}
\hline Compound & $\log (D)\left(m^{2} S^{-1}\right)$ & $\begin{array}{l}\text { Hydrodynamic } \\
\text { radius (m) }\end{array}$ & $\begin{array}{l}\text { Hydrodynamic } \\
\text { volume }\left(\mathrm{m}^{3}\right)\end{array}$ & $\begin{array}{l}\text { Relative } \\
\text { volumes }\end{array}$ \\
\hline Zinc & -9.09 & $3.02 \times 10^{-10}$ & $1.15 \times 10^{-28}$ & 1 \\
\hline $\mathrm{RM}$ & -9.28 & $4.67 \times 10^{-10}$ & $4.27 \times 10^{-28}$ & 3.7 \\
\hline
\end{tabular}

Table 3: Copper contents $\left(\mathrm{ppb} / \mathrm{LL}^{\mathrm{a}}\right.$ or $\left.\mathrm{ppb} / \mathrm{g}^{\mathrm{b}}\right)$ in plasma and tissues 24 hours after RM191A or gel treatment in mice.

\begin{tabular}{|c|c|c|c|c|}
\hline & Plasma $^{a}$ & Liver $^{\mathrm{b}}$ & Kidney $^{\mathbf{b}}$ & Brain $^{b}$ \\
\hline Gel $(n=9)$ & $0.173 \pm 0.007$ & $744.05 \pm 112.01$ & $626.46 \pm 23.11$ & $486.18 \pm 37.02$ \\
\hline RM191A $(n=9)$ & $0.170 \pm 0.005$ & $826.02 \pm 203.66$ & $591.74 \pm 30.46$ & $543.56 \pm 102.60$ \\
\hline
\end{tabular}

\section{FIGURES}

Figure 1: Synthesis and characterization of RM191A

(A) Picture of RM191A solution. (B) Fluorescence emission spectrum of RM191A and CuEDTA. (C) Cryo-TEM images of blank (top) and RM191A (bottom). (D) Structure of RM191A crystal from X-ray single-crystal analysis $($ Red $=$ oxygen, blue $=$ nitrogen, light red $=$ copper, dark grey $=$ carbon, light grey $=$ hydrogen). $(\mathrm{E})$ Cyclic Voltammetry results of RM191A showing two reduction peaks and one oxidation peak.

Figure 2: RM191A has potent antioxidant and anti-inflammatory properties (A) Comparison of superoxide scavenging activities of both bovine SOD1 and RM191A ( $\mathrm{n}$ $=3$ ) at $560 \mathrm{~nm}$. (B) Dose dependent curve of RM191A for N27 cells, as measured by PI exclusion (PI -ve) in flow cytometry $(n=6)$. (C) Percentage live N27 cells, as measured by $\mathrm{PI}$ exclusion (PI -ve) in flow cytometry, exposed to $200 \mu \mathrm{M}$ hydrogen peroxide for 30 minutes and then treated with $21 \mu \mathrm{g} / \mathrm{mL}$ RM191A or gel for $4 \mathrm{hrs}(\mathrm{n}=6)$. (D) Dose dependent curve of RM191A for RAW 264.7 cells, as measured by MTT assay $(n=8)$. (E) Amount of ROS generated by RAW 264.7 cells, as measured by $\mathrm{CM}-\mathrm{H}_{2}$ DCFDA fluorescence in flow cytometry, upon LPS $(10 \mathrm{ng} / \mathrm{mL})$ stimulation and followed by treatment with RM191A or gel only $(n=6)$. (F) Adult normal human dermal fibroblasts (NHDF) viability at different doses of RM191A, as measured by PI exclusion (PI -ve) in flow cytometry $(n=6)$. Heat map generated from the $C_{T}$ values in PCR arrays reflecting (G) Oxidative Stress, (H) Chemokines and Receptors and (I) Pain-associated gene expression in NHDF treated with or without RM191A. The $C_{T}$ cut-off was set to 36 .

Data expressed as mean \pm SEM. ${ }^{*} p<0.05$ and ${ }^{* * *} p<0.0005$ by t-test.

Figure 3: RM191A protects against UV-induced oxidative stress 
(A) Representative images of immunohistochemical staining of CPDs in human skin explants from UV-exposed explants. Analysis of CPD in epidermis of skin explants. (B) Representative images of immunohistochemical staining of 8-oxoG in human skin explants from UV-exposed explants. Analysis of 8-oxoG in epidermis and dermis of skin explants. (C) Representative images of immunohistochemical staining of $8 N G O$ in human skin explants from UV-exposed explants. Analysis of 8NGO in epidermis and dermis of skin explants. The maginified (120X) images of each stainings are shown in the insets. The red stain in the 8-oxoG is in the cytoplasm and the nuclei in the RM191A treated groups are considerably less stained.

Data expressed as mean \pm SEM. ${ }^{* *} p<0.001$ and $N S=$ not significant by One-way ANOVA between data sets ( $n=3$ explants per data point).

Figure 4: RM191A is non-toxic and readily bioavailable in mice

(A) Body weights $(\mathrm{g})$ of mice treated with different topical doses of RM191A gel or gel (control) for 4 days $(n=5)$. (B) Body weights $(g)$ in mice treated with topical doses of RM191A $(0.19 \mathrm{~mL} / \mathrm{kg})$ or gel for 29 days $(n=4-9)$. Copper levels in $(C)$ skin, (D) liver, $(E)$ lymph nodes and $(F)$ faeces over time measured using ICP-MS $(n=4$ per time point).

Data expressed as mean \pm SEM. ${ }^{*} p<0.05,{ }^{* *} p<0.005,{ }^{* * *} p<0.0005$ and ${ }^{* * * *} p<0.00005$ by One-way ANOVA.

Figure 5: RM191A attenuates inflammation and improves wound healing in mice (A) Representative H\&E staining images of ear sections and ear weights from mice pretreated with RM191A or gel, and then with TPA $(n=6)$. The arrowheads indicate the infiltrated leukocytes. (B) Representative images of wound areas and percentage wound closure in mice treated with RM191A or gel $(n=9)$. The representative H\&E staining images of wound sections on Day 12 are shown in the right.

Data expressed as mean \pm SEM. ${ }^{*} p<0.05,{ }^{* *} p<0.005,{ }^{* * *} p<0.0005$ and ${ }^{* * * *} p<0.00005$ by t-test or One-way ANOVA. 


\section{Figure 1}
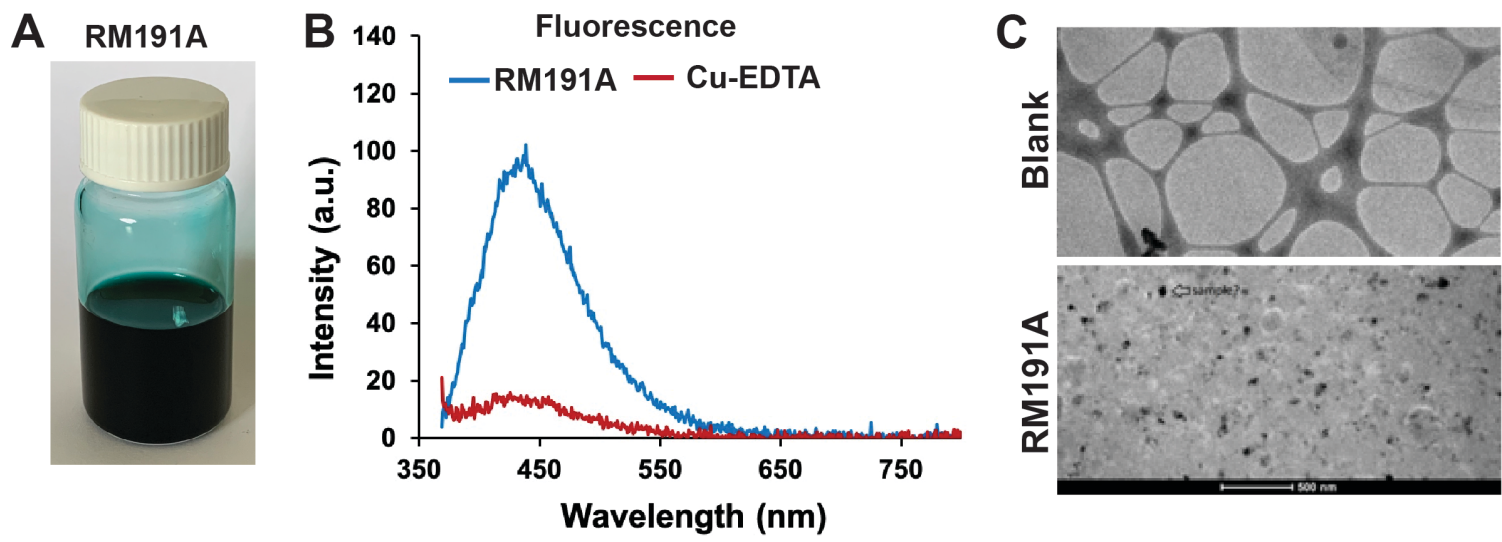

D

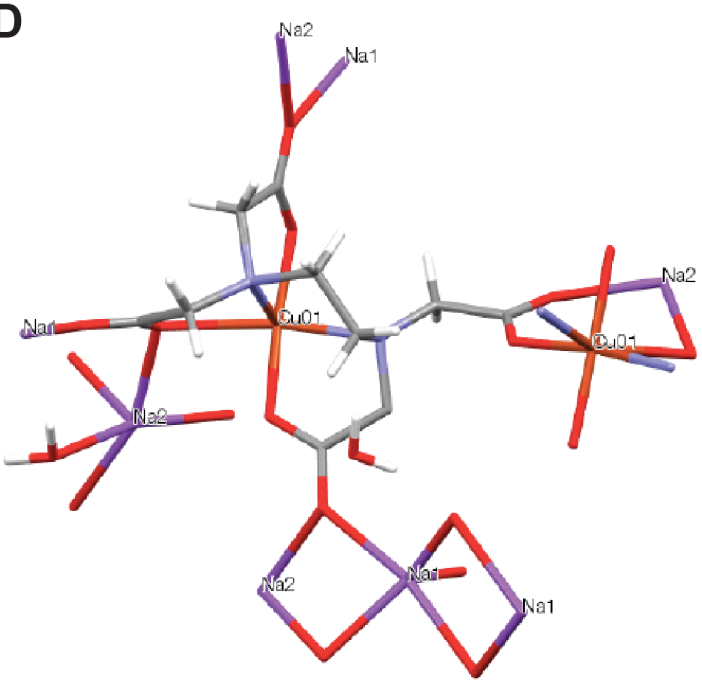

E

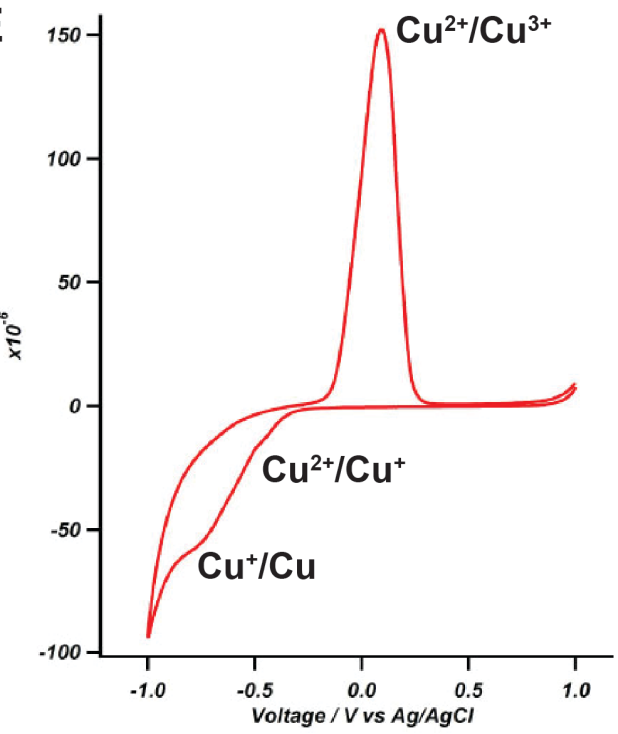




\section{Figure 2}

A

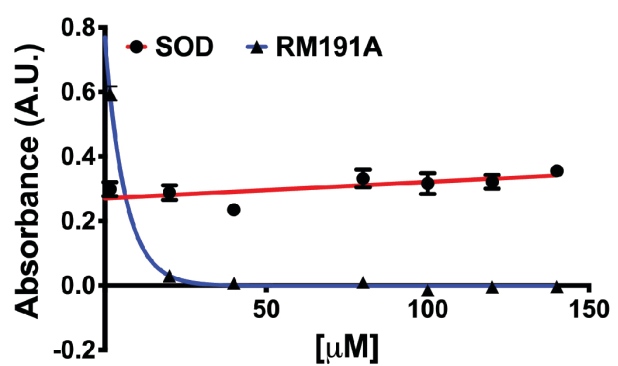

C

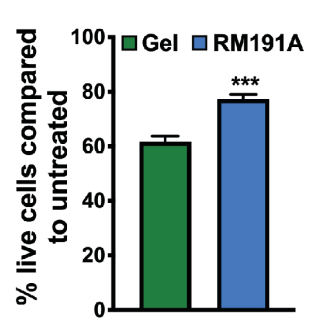

D

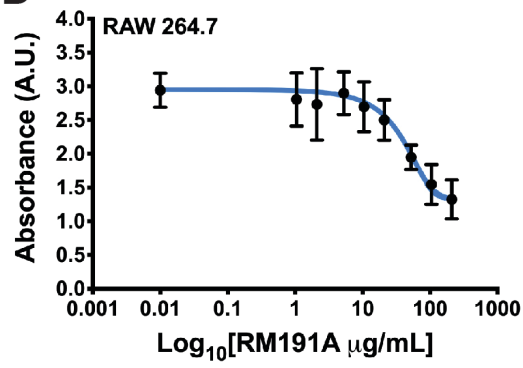

E

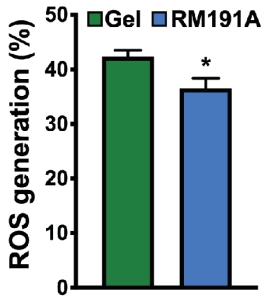

$F$

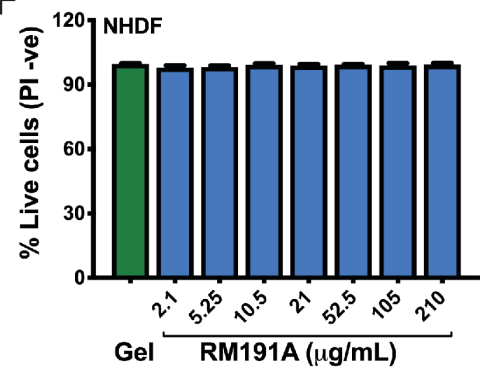

B

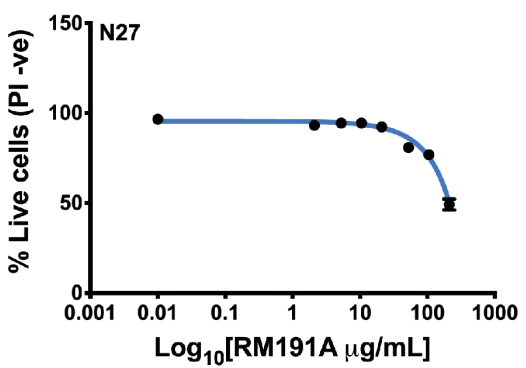

H Chemokines I Pain: Neuopathic \& Receptors \& Inflammatory

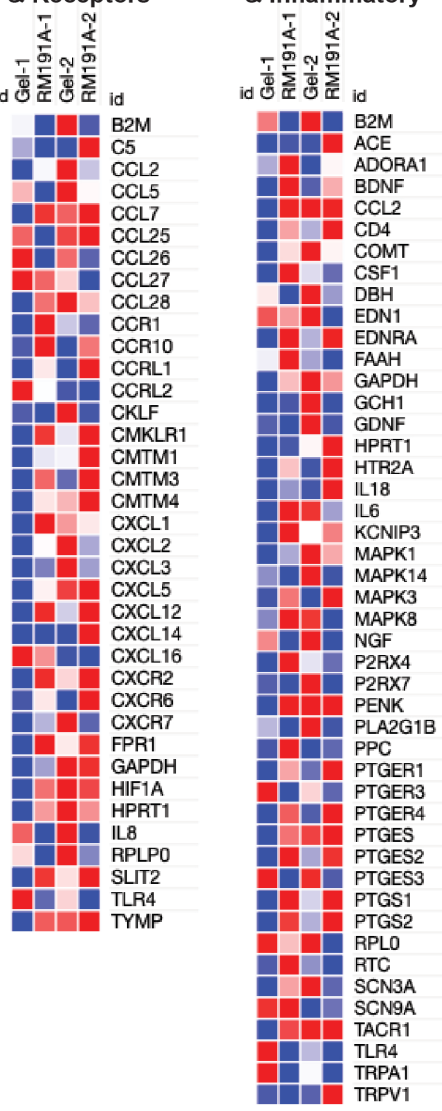

Min

Max 


\section{Figure 3}

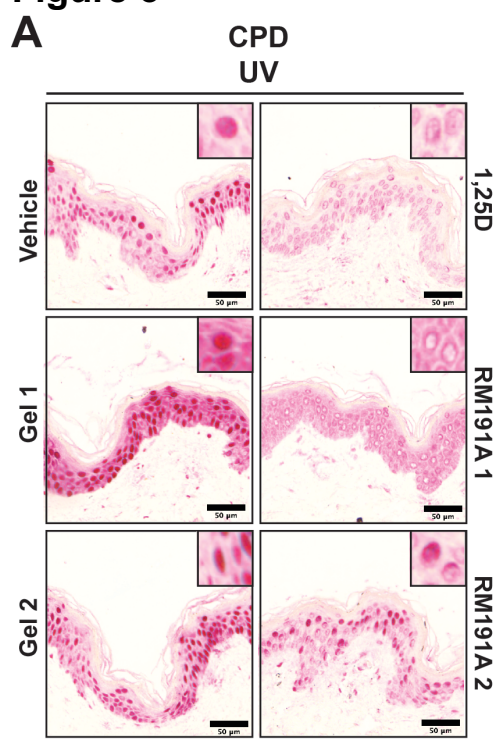

Epidermis
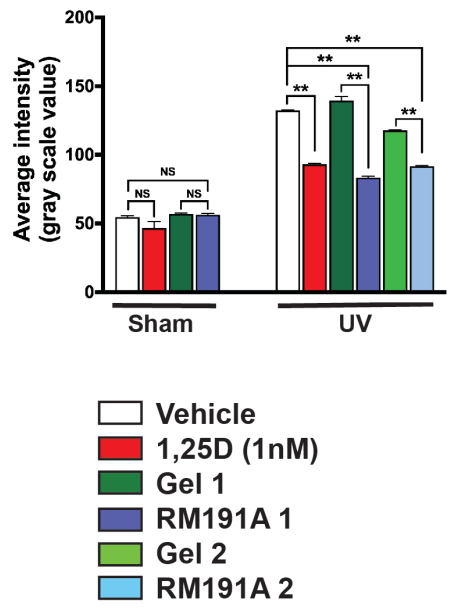

B

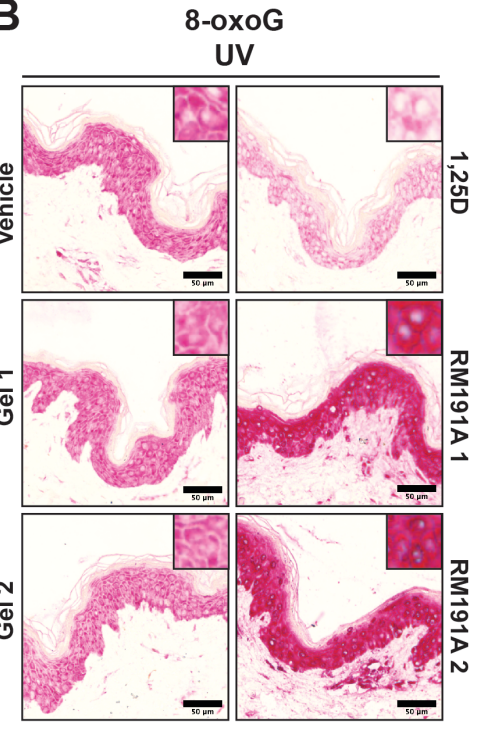

Epidermis
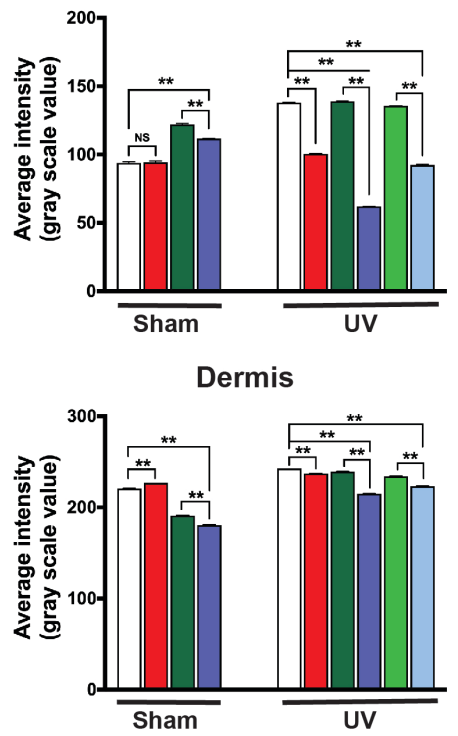

C $\quad$ 8NGO

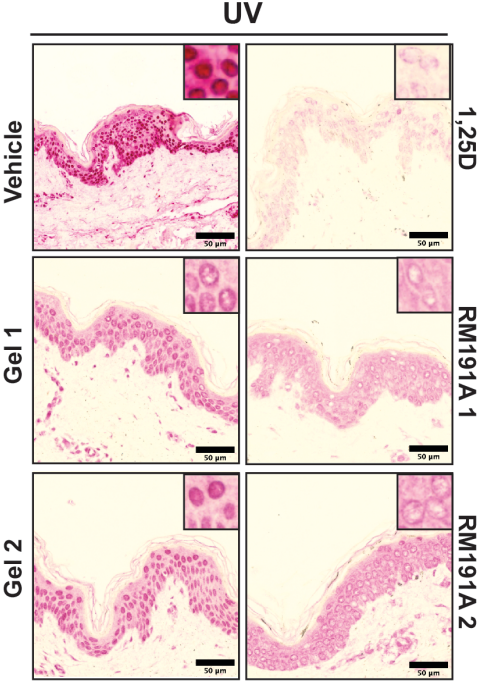

Epidermis
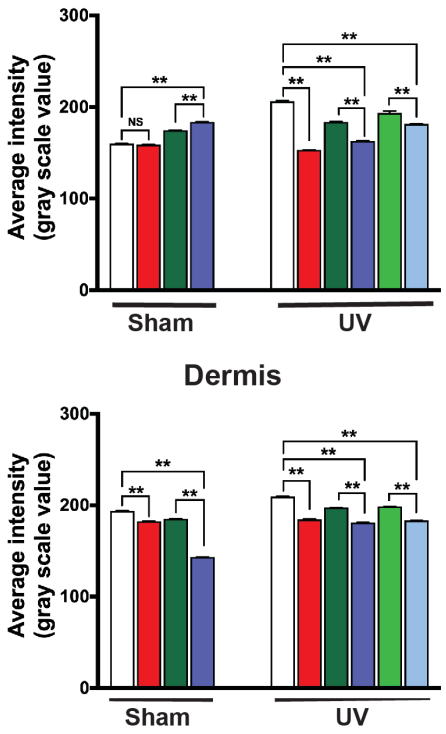


\section{Figure 4}

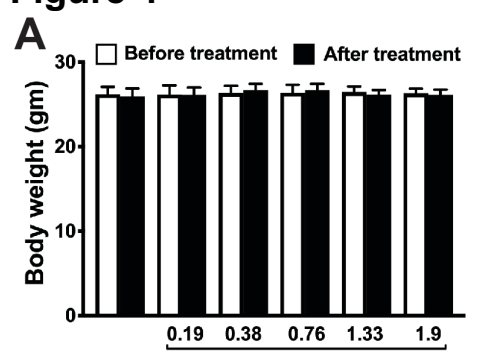

Gel RM191A (mL/kg)

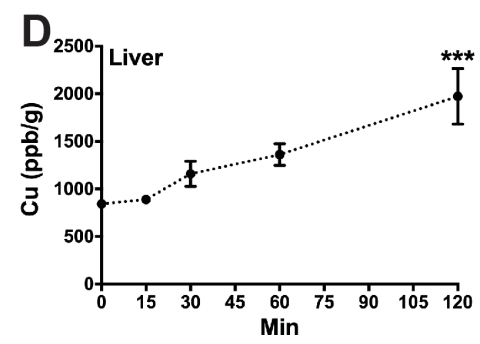

B

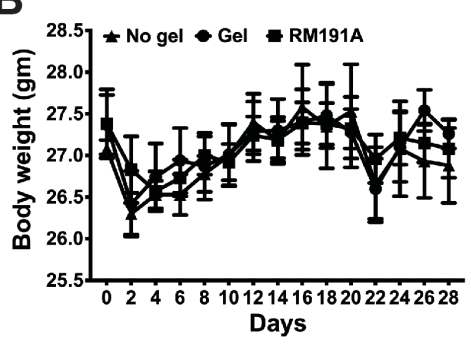

E

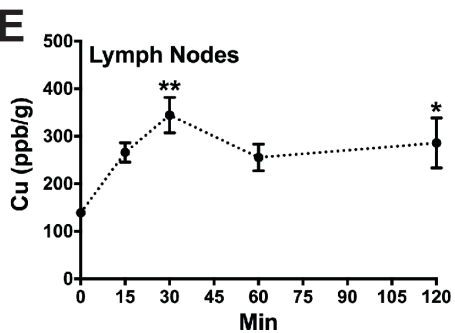

C
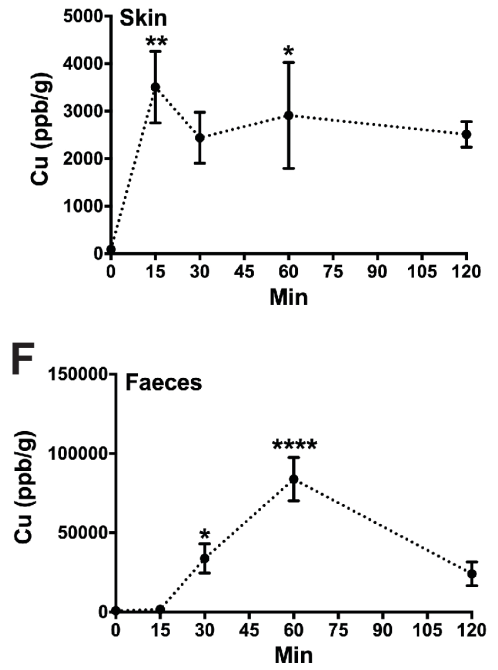

Figure 5

A
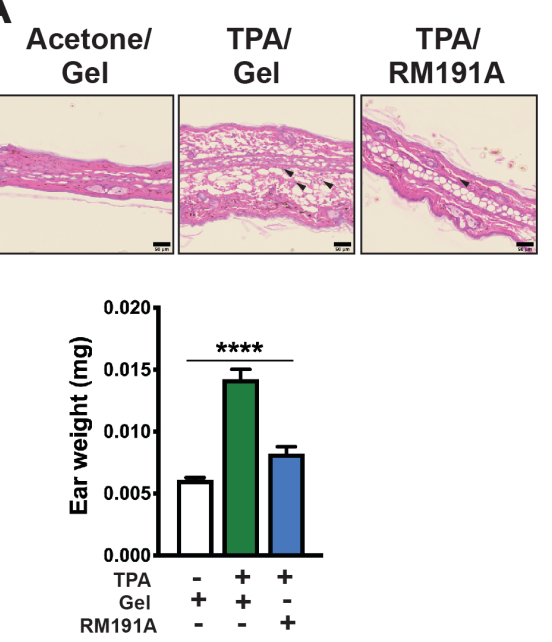

B
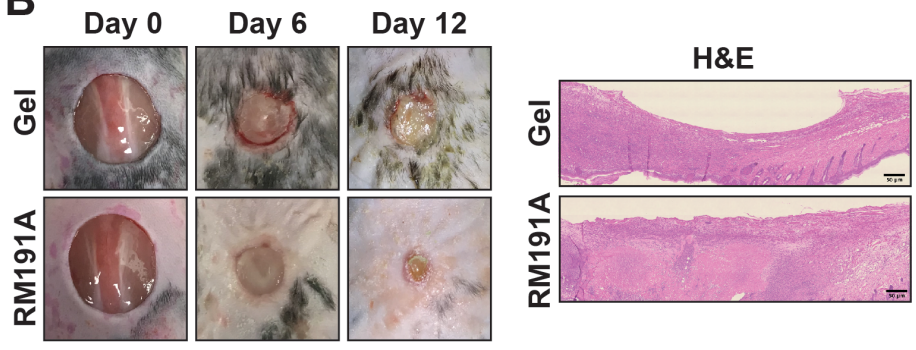

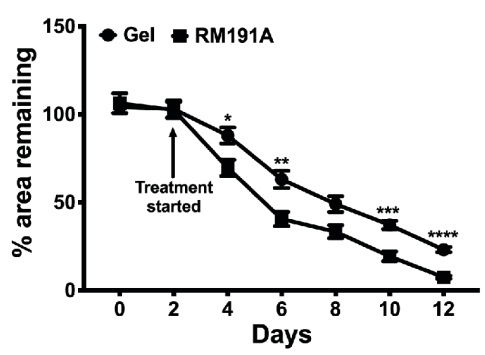




\section{SUPPLEMENTAL TABLES}

Table S1: Fold change in key oxidative stress gene expression in RM191A-treated NHDF compared to control

\begin{tabular}{|l|r|}
\hline Gene & $\begin{array}{r}\text { Fold } \\
\text { Change }\end{array}$ \\
\hline HMOX1 (Heme oxygenase (decycling) 1) & 67.56 \\
\hline $\begin{array}{l}\text { SLC7A11 (Solute carrier family 7 (anionic amino acid transporter light } \\
\text { chain, xc- system), member 11) }\end{array}$ & 8.53 \\
\hline HSPA1A (Heat shock 70kDa protein 1A) & 7.45 \\
\hline SRXN1 (Sulfiredoxin 1) & 6.18 \\
\hline GCLM (Glutamate-cysteine ligase, modifier subunit) & 5.75 \\
\hline TXNRD1 (Thioredoxin reductase 1) & 5.27 \\
\hline SQSTM1 (Sequestosome 1) & 2.19 \\
\hline NQO1 (NAD(P)H dehydrogenase, quinone 1) & 2.02 \\
\hline EPX (Eosinophil peroxidase) & -2.28 \\
\hline NOX4 (NADPH oxidase 4) & -3.90 \\
\hline
\end{tabular}

Fold regulation cut off $=2, p$-value cut off $=0.05$

Table S2: Fold change in key inflammatory gene expression in RM191A-treated NHDF compared to control

\begin{tabular}{|l|r|}
\hline Gene & Fold Change \\
\hline IL8 (Interleukin 8) & 6.31 \\
\hline CCL26 (Chemokine (C-C motif) ligand 26) & 4.25 \\
\hline TLR4 (Toll-like receptor 4) & 2.30 \\
\hline CCL7 (Chemokine (C-C motif) ligand 7) & -2.19 \\
\hline CXCR6 (Chemokine (C-X-C motif) receptor 6) & -2.80 \\
\hline CCRL1 (Chemokine (C-C motif) receptor-like 1) & -3.30 \\
\hline CMKLR1 (Chemokine-like receptor 1) & -6.18 \\
\hline
\end{tabular}

Fold regulation cut off $=2, p$-value cut off $=0.05$

Table S3: Fold change in key pain gene expression in RM191A-treated NHDF compared to control

\begin{tabular}{|l|r|}
\hline Gene & Fold Change \\
\hline PLA2G1B (Phospholipase A2, group IB (pancreas)) & 2.32 \\
\hline PTGS2 (Prostaglandin E synthase 2) & -2.10 \\
\hline PTGER1 (Prostaglandin E receptor 1 (subtype EP1), 42kDa) & -2.16 \\
\hline IL18 (Interleukin 18 (interferon-gamma-inducing factor) & -2.25 \\
\hline
\end{tabular}




\begin{tabular}{|l|r|}
\hline ADORA1 (Adenosine A1 receptor) & -2.57 \\
\hline EDNRA (Endothelin receptor type A) & -2.64 \\
\hline KCNIP3 (Kv channel interacting protein 3, calsenilin) & -3.04 \\
\hline HTR2A (5-hydroxytryptamine (serotonin) receptor 2A) & -7.00 \\
\hline
\end{tabular}

Fold regulation cut off $=2, p$-value cut off $=0.05$

Table S4: Tissue weights $(\mathrm{g})$ in mice treated with different topical doses $(\mathrm{mL} / \mathrm{kg})$ of RM191A or gel (control) for 4 days

\begin{tabular}{|c|c|c|c|c|c|c|}
\hline Tissues & Gel & $\begin{array}{c}\text { RM191A } \\
(0.19)\end{array}$ & $\begin{array}{c}\text { RM191A } \\
(0.38)\end{array}$ & $\begin{array}{c}\text { RM191A } \\
(0.76)\end{array}$ & $\begin{array}{c}\text { RM191A } \\
(1.33)\end{array}$ & $\begin{array}{c}\text { RM191A } \\
(1.90)\end{array}$ \\
\hline Thymus & $\begin{array}{l}0.025 \pm \\
0.006\end{array}$ & $\begin{array}{l}0.024 \quad \pm \\
0.002\end{array}$ & $\begin{array}{l}0.019 \quad \pm \\
0.004\end{array}$ & $\begin{array}{l}0.020 \\
0.006\end{array}$ & $\begin{array}{ll}0.023 & \pm \\
0.003\end{array}$ & $\begin{array}{l}0.022 \quad \pm \\
0.003\end{array}$ \\
\hline Heart & $\begin{array}{l}0.127 \pm \\
0.011\end{array}$ & $\begin{array}{l}0.138 \\
0.005 \\
\end{array}$ & $\begin{array}{l}0.139 \\
0.011\end{array}$ & $\begin{array}{ll}0.139 & \pm \\
0.017 & \end{array}$ & $\begin{array}{l}0.139 \quad \pm \\
0.015\end{array}$ & $\begin{array}{l}0.137 \\
0.019\end{array}$ \\
\hline Liver & $\begin{array}{l}1.170 \pm \\
0.143\end{array}$ & $\begin{array}{l}1.076 \\
0.244 \\
\end{array}$ & $\begin{array}{l}1.118 \\
0.259 \\
\end{array}$ & $\begin{array}{ll}1.249 & \pm \\
0.237 & \\
\end{array}$ & $\begin{array}{l}1.262 \pm \\
0.112\end{array}$ & $\begin{array}{l}1.282 \\
0.068 \\
\end{array}$ \\
\hline Spleen & $\begin{array}{l}0.068 \pm \\
0.008\end{array}$ & $\begin{array}{l}0.080 \\
0.010\end{array}$ & $\begin{array}{ll}0.080 \quad \pm \\
0.012\end{array}$ & $\begin{array}{ll}0.078 \quad \pm \\
0.006\end{array}$ & $\begin{array}{l}0.074 \quad \pm \\
0.012\end{array}$ & $\begin{array}{l}0.079 \\
0.013\end{array}$ \\
\hline Kidney & $\begin{array}{l}0.163 \pm \\
0.020\end{array}$ & $\begin{array}{l}0.169 \\
0.012\end{array}$ & $\begin{array}{l}0.170 \\
0.014\end{array}$ & $\begin{array}{l}0.158 \\
0.019\end{array}$ & $\begin{array}{l}0.152 \\
0.009\end{array}$ & $\begin{array}{l}0.155 \\
0.004\end{array}$ \\
\hline Lymph Nodes & $\begin{array}{l}0.019 \pm \\
0.004\end{array}$ & $\begin{array}{l}0.016 \\
0.004 \\
\end{array}$ & $\begin{array}{l}0.017 \\
0.001\end{array}$ & $\begin{array}{l}0.019 \\
0.003 \\
\end{array}$ & $\begin{array}{ll}0.020 & \pm \\
0.002\end{array}$ & $\begin{array}{l}0.021 \\
0.004\end{array}$ \\
\hline Gastrocnemius & $\begin{array}{l}0.150 \pm \\
0.007\end{array}$ & $\begin{array}{ll}0.152 & \pm \\
0.014\end{array}$ & $\begin{array}{l}0.154 \\
0.009 \\
\end{array}$ & $\begin{array}{l}0.153 \\
0.015 \\
\end{array}$ & $\begin{array}{ll}0.148 & \pm \\
0.004\end{array}$ & $\begin{array}{l}0.157 \\
0.015 \\
\end{array}$ \\
\hline Quadriceps & $\begin{array}{l}0.175 \pm \\
0.014\end{array}$ & $\begin{array}{l}0.168 \\
0.015\end{array}$ & $\begin{array}{l}0.173 \\
0.028\end{array}$ & $\begin{array}{l}0.203 \\
0.023\end{array}$ & $\begin{array}{l}0.211 \\
0.013\end{array}$ & $\begin{array}{l}0.190 \\
0.015\end{array}$ \\
\hline Testes & $\begin{array}{l}0.098 \pm \\
0.012 \\
\end{array}$ & $\begin{array}{l}0.095 \\
0.006 \\
\end{array}$ & $\begin{array}{l}0.097 \\
0.006 \\
\end{array}$ & $\begin{array}{l}0.094 \\
0.009 \\
\end{array}$ & $\begin{array}{l}0.100 \quad \pm \\
0.005\end{array}$ & $\begin{array}{l}0.093 \\
0.018\end{array}$ \\
\hline Brain & $\begin{array}{l}0.432 \pm \\
0.030\end{array}$ & $\begin{array}{ll}0.437 & \pm \\
0.043 & \end{array}$ & $\begin{array}{ll}0.466 & \pm \\
0.031 & \end{array}$ & $\begin{array}{l}0.452 \\
0.022\end{array}$ & $\begin{array}{ll}0.439 & \pm \\
0.011 & \end{array}$ & $\begin{array}{l}0.438 \\
0.010\end{array}$ \\
\hline
\end{tabular}

$\mathrm{n}=5$ per group

Table S5: Tissue weights $(\mathrm{g})$ in mice treated with topical doses of RM191A (0.19 $\mathrm{mL} / \mathrm{kg}$ body weight) or gel (control) for 29 days

\begin{tabular}{|l|l|l|l|}
\hline Tissues & No gel $(\mathbf{n}=\mathbf{4})$ & Gel $(\mathbf{n}=\mathbf{9})$ & RM191A (n = 9) \\
\hline Thymus & $0.025 \pm 0.003$ & $0.025 \pm 0.003$ & $0.023 \pm 0.005$ \\
\hline Heart & $0.131 \pm 0.008$ & $0.141 \pm 0.016$ & $0.139 \pm 0.014$ \\
\hline Liver & $1.123 \pm 0.052$ & $1.213 \pm 0.115$ & $1.156 \pm 0.136$ \\
\hline Spleen & $0.074 \pm 0.003$ & $0.067 \pm 0.007$ & $0.069 \pm 0.013$ \\
\hline Kidney & $0.152 \pm 0.012$ & $0.167 \pm 0.016$ & $0.174 \pm 0.011$ \\
\hline Lymph Nodes & $0.020 \pm 0.004$ & $0.018 \pm 0.004$ & $0.016 \pm 0.004$ \\
\hline Gastrocnemius & $0.160 \pm 0.004$ & $0.162 \pm 0.009$ & $0.163 \pm 0.012$ \\
\hline
\end{tabular}




\begin{tabular}{|l|l|l|l|}
\hline Quadriceps & $0.193 \pm 0.023$ & $0.195 \pm 0.023$ & $0.192 \pm 0.022$ \\
\hline Testes & $0.113 \pm 0.007$ & $0.106 \pm 0.009$ & $0.104 \pm 0.006$ \\
\hline Brain & $0.413 \pm 0.025$ & $0.435 \pm 0.015$ & $0.448 \pm 0.024$ \\
\hline
\end{tabular}

\section{SUPPLEMENTAL FIGURES}

\section{Figure S1: Synthesis and characterization of RM191A}

(A) UV-visible spectrum of RM191 and Cu-EDTA complex. (B) FTIR spectrum of RM191A.

(C) DOSY 2D spectrum of EDTA-Zinc complex and RM191A in $D_{2} \mathrm{O}$. (D) White light micrograph of RM191A crystals. (E) Cyclic Voltammetry results of RM191A showing two reduction peaks and one oxidation peak.

Figure S2: RM191A has potent antioxidant and anti-inflammatory properties (A) UV-visible spectrum of RM191 and bovine SOD1. (B) Dose dependent curve of RM191A for N27 cells, as measured by MTT assay $(n=8)$. (C) Dose dependent curve of RM191A for HUVEC, as measured by PI exclusion (PI -ve) in flow cytometry ( $n=6)$. (D) Dose dependent curve of RM191A for RAW 264.7 cells, as measured by PI exclusion (PI -ve) in flow cytometry $(n=6)$. (E) Reduction potential of $\mathrm{Cu}$ at various oxidative states present in SOD and RM191A.

Figure S3: RM191A protects against UV-induced oxidative stress

(A) A comparison of the output of natural sunlight with the Oriel $450 \mathrm{~W}$ solar simulator containing an atmospheric attenuation filter. The dotted line represents the output of natural sunlight at midday in October in Sydney, Australia, while the solid line represents the output of the solar simulator used in all experiments in human explant skin. While the output of the solar simulator closely resembles that of natural sunlight, the former emits $10 \%$ UVB, while the latter emits $5 \%$ UVB. (B) Representative images of immunohistochemical staining of CPDs in human explants from isotype control and sham exposed explants. There was little staining in the isotype control. Sham irradiated skin showed low levels of nuclear staining. (C) Representative images of immunohistochemical staining of 8-oxoG in human explants from isotype control and sham exposed explants. (D) Representative images of immunohistochemical staining of 8 NGO in human explants from isotype control and sham exposed explants.

Figure S4: RM191A is non-toxic and readily bioavailable in mice

(A) Water and food consumption, (B) EchoMRI, (C) rotarod performance and (D) rearing behaviour of mice untreated and treated with topical doses of RM191A $(0.19 \mathrm{~mL} / \mathrm{kg})$ or gel (control) for 29 days $(n=9)$. (E) H\&E staining of heart, kidney, liver and skin from mice untreated and treated with topical doses of RM191A or gel for 29 days. Copper levels in $(F)$ kidney, $(\mathrm{G})$ plasma, $(\mathrm{H})$ urine and $(\mathrm{I})$ brain over time measured using ICP-MS $(\mathrm{n}=4)$. (J) Percentage transmission of RM191A over time in the in vitro blood-brain-barrier model $(n=2)$. 


\section{Figure S1}

A

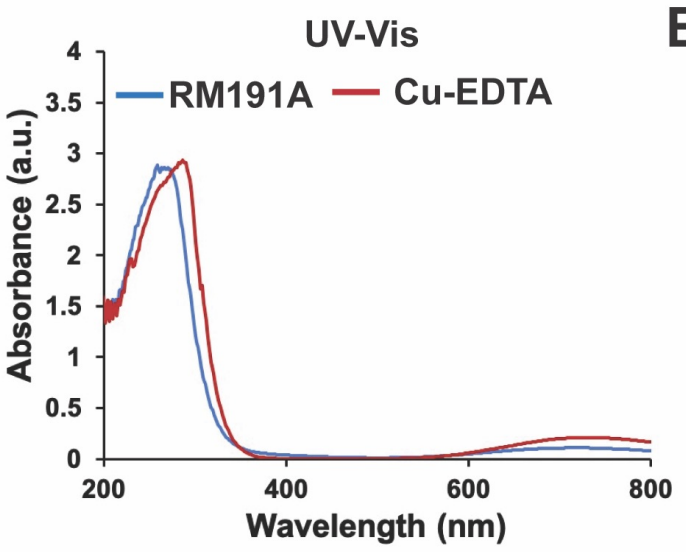

C
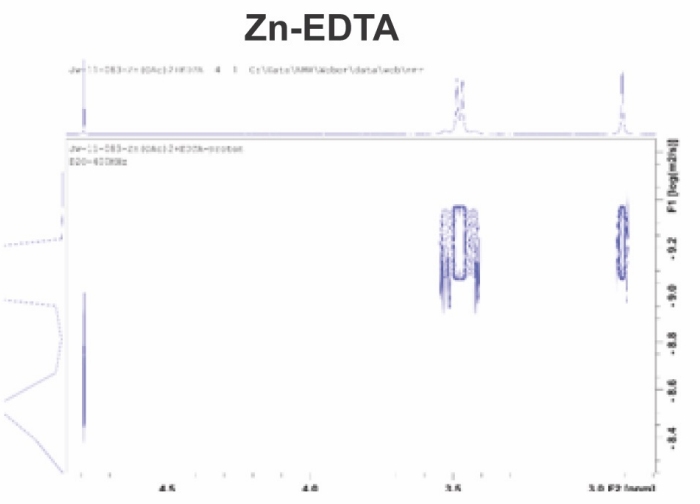

D

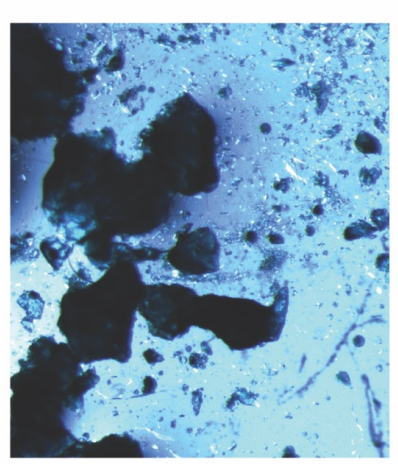

B

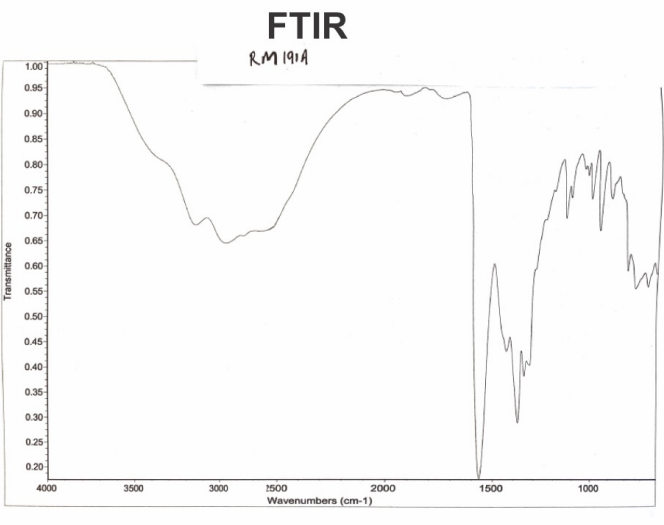

\section{RM191A}
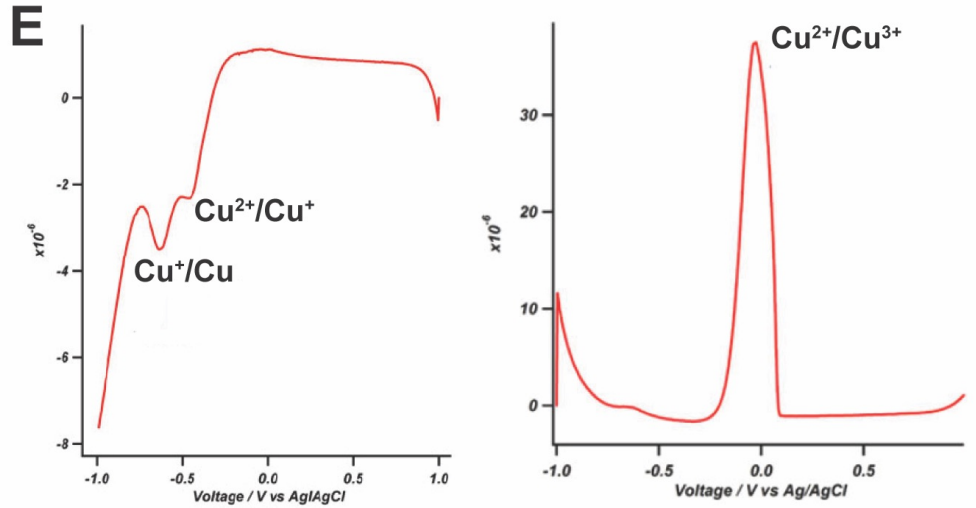
Figure S2
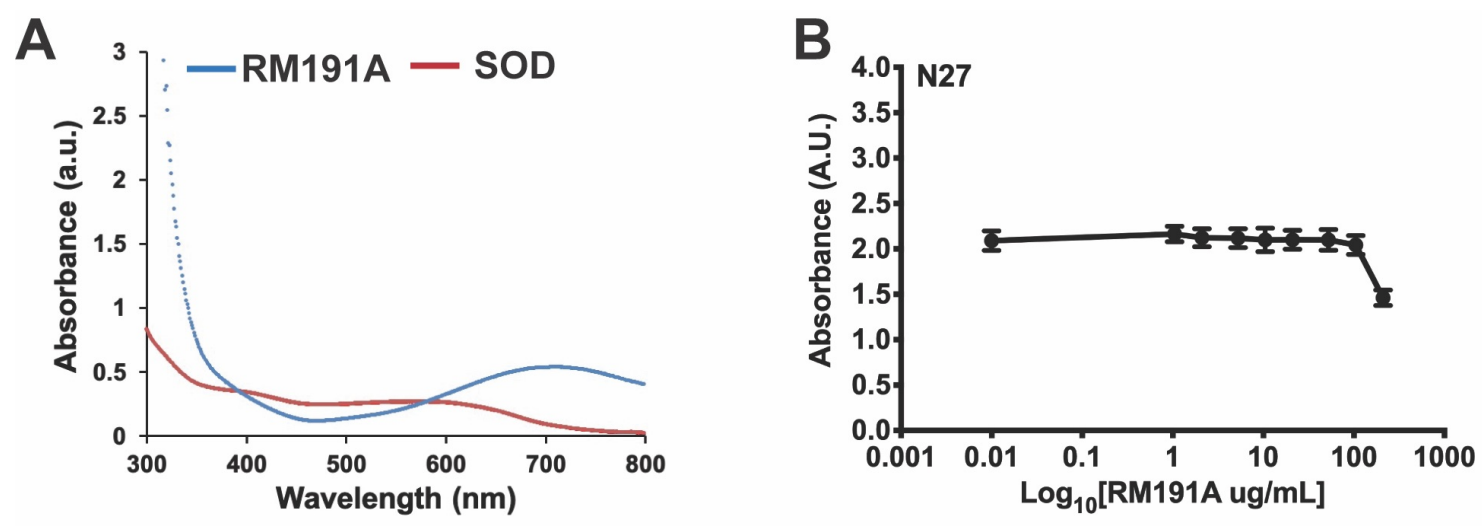

C
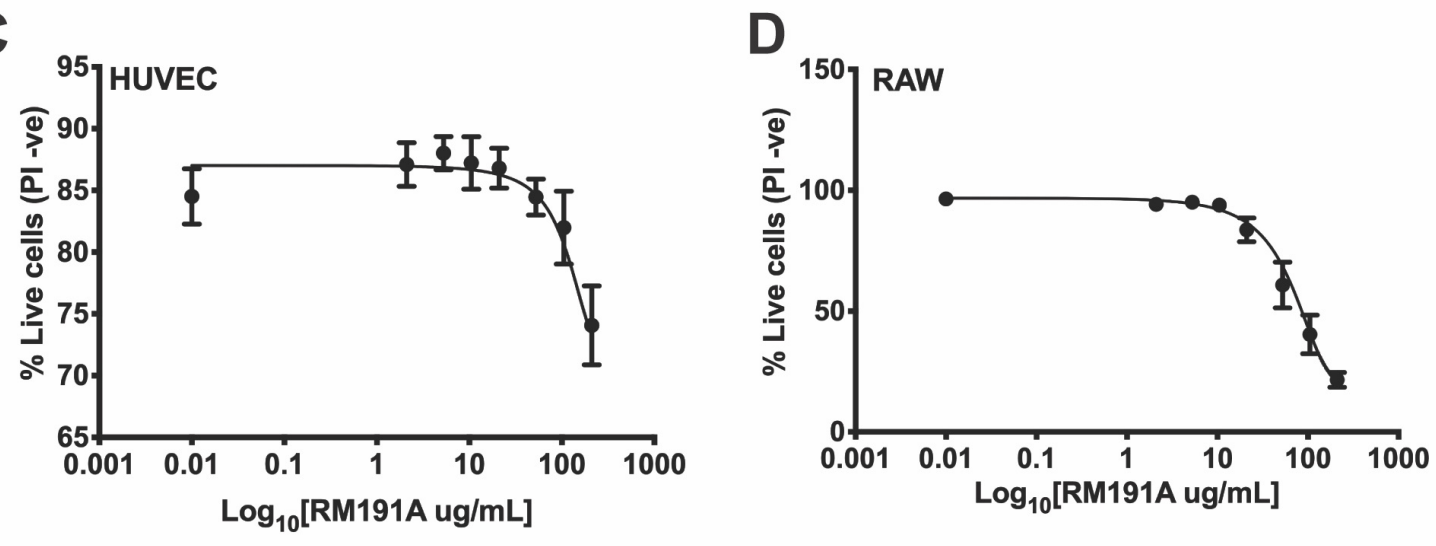

E

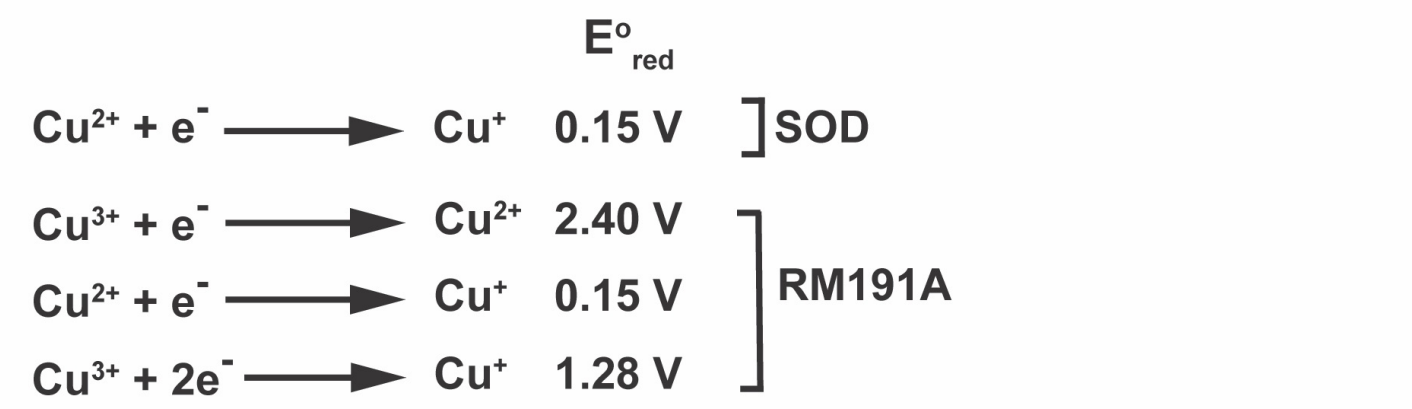




\section{Figure S3}
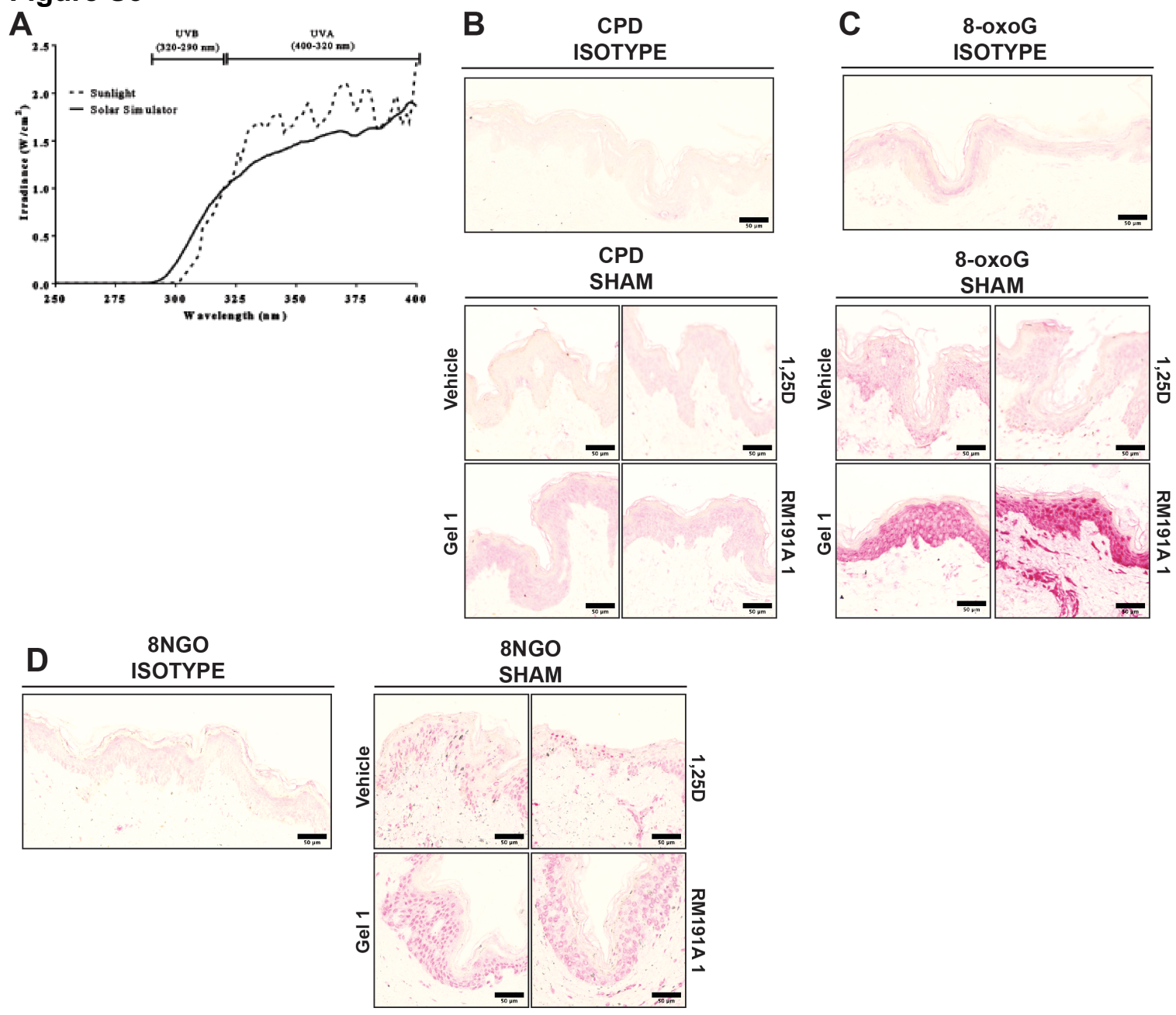


\section{Figure S4}
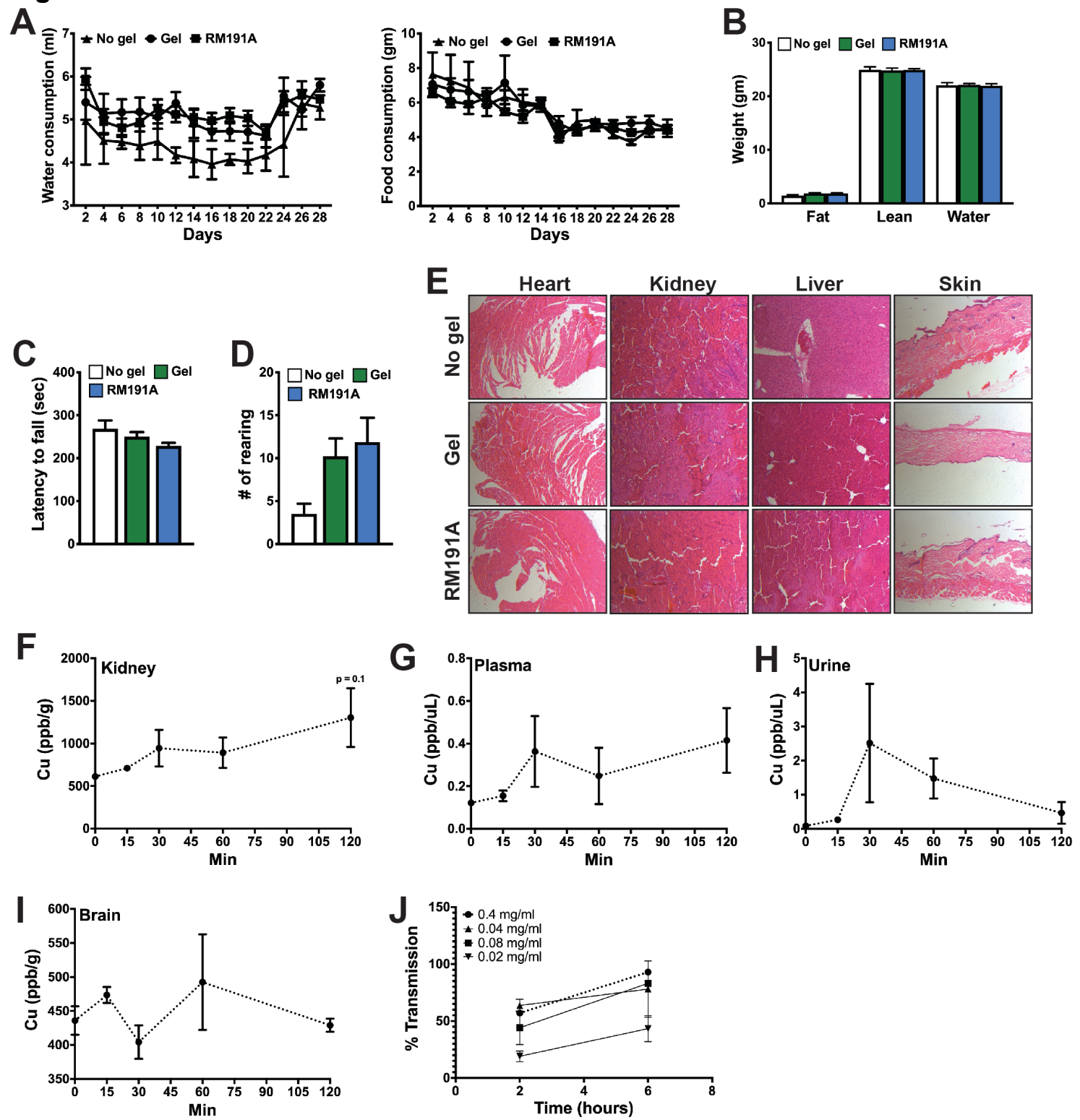
bioRxiv preprint doi: https://doi.org/10.1101/2020.05.10.086694; this version posted May 11, 2020. The copyright holder for this preprint (which

was not certified by peer review) is the author/funder, who has granted bioRxiv a license to display the preprint in perpetuity. It is made available under aCC-BY-NC-ND 4.0 International license.

\section{Graphical Abstract}

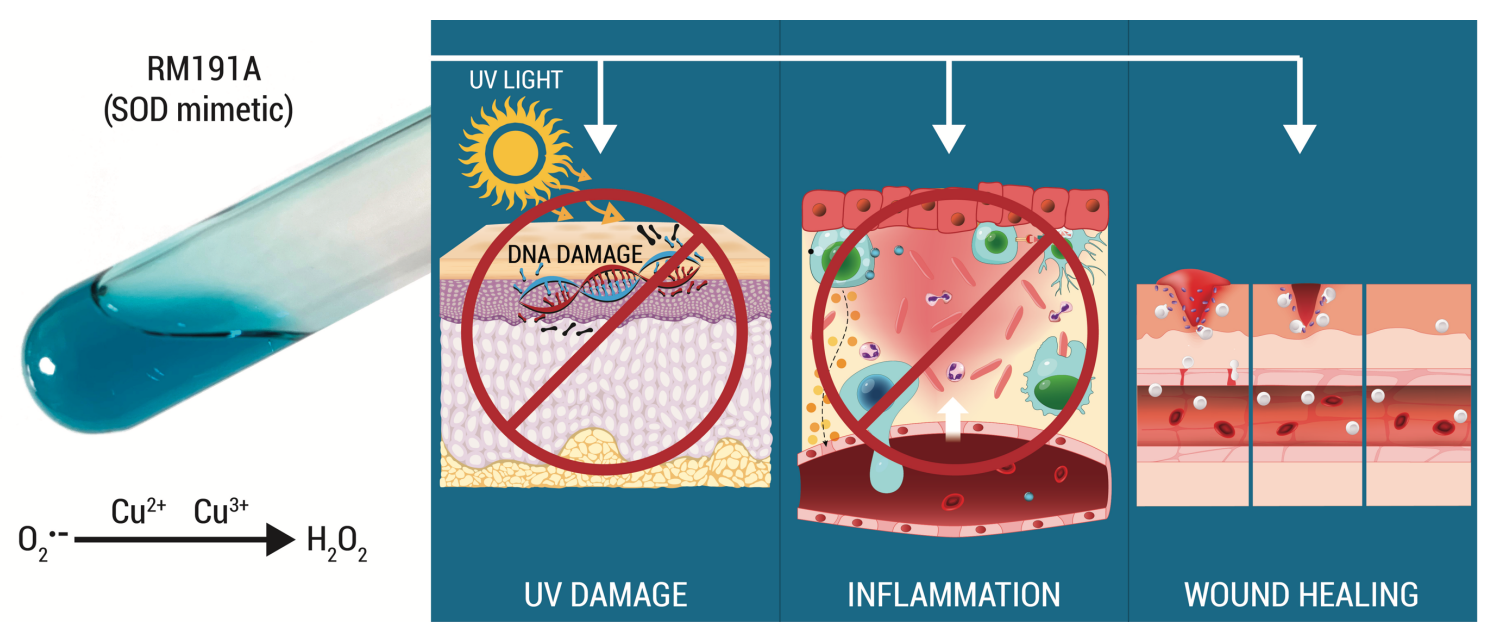

